\title{
From One to Many Central Plans: \\ Drug Advertising Inspections and Intra-National Protectionism in China*
}

\author{
Markus Eberhardt ${ }^{a, b, c} \quad$ Zheng Wang ${ }^{a, d} \quad$ Zhihong $\mathrm{Yu}^{a, b, e}$ \\ ${ }^{a}$ Globalisation and Economic Policy Centre (GEP), University of Nottingham \\ ${ }^{b}$ School of Economics, University of Nottingham \\ ${ }^{c}$ Centre for the Study of African Economies (CASE), University of Oxford \\ ${ }^{d}$ Hull University Business School \\ ${ }^{e}$ CESifo, Munich
}

October 9, 2015

Accepted for publication in Journal of Comparative Economics

\begin{abstract}
This paper provides the first micro-level evidence for the existence and patterns of intra-national protectionism in China. We demonstrate that drug advertising inspections are used by provincial governments to discriminate against firms from outside the province. We further reveal systematic patterns in the degree of discrimination across firms: those from neighboring areas, those from regions with more economic links to the destination province, those from provinces with stronger presence in the market, and those with political ties to "allied" provincial governments are less likely to be targeted. Our findings highlight the unique politico-economic structure in China and confirm that giving local governments strong incentives to compete with each other may exacerbate the market distortions inherent in a partially reformed economy.
\end{abstract}

Key Words: Intra-national protectionism; Drug advertising; China

JEL Classifications: F15, L25, P26

${ }^{*}$ Corresponding author: Zheng Wang, Hull University Business School, Hull, HU6 7RX, United Kingdom. Email: z.wang@hull.ac.uk. We thank the editor, two anonymous referees, and participants at various conferences and seminars for helpful comments and suggestions. Wang gratefully acknowledges financial support from the University of Nottingham and Shanghai Research Institute of Strategic Trade and Development for this research. The usual disclaimers apply. 
"Although the central government has released control over prices, outputs, and enterprise budgets, these functions have been taken up, albeit in a less systematic fashion, by local governments. Thus, China has moved from having one central plan to having many, mutually competitive, central plans." Young (2000, p. 1129)

"[A]ccording to Espicom, discrimination [by provincial governments] in favor of locally produced drugs is an accepted practice [in China]." Deloitte (2011, p. 23)

\section{Introduction}

The analysis of barriers to trade within countries has received growing attention in the recent literature (e.g. Atkin and Donaldson, 2015; Coşar and Fajgelbaum, forthcoming; Coughlin and Novy, 2013; Ramondo et al., 2014). Barriers to domestic economic activity are to a large extent created by intra-national protectionism, preventing the efficient allocation of resources and attenuating the benefits of scale economies and spatial spillovers within the economy, as well as offsetting potential gains from a more liberal international trade environment. This argument is particularly relevant for China as it made a strong commitment to further open up domestic markets upon joining the WTO in 2001. Nevertheless, existing research suggests limited improvement in domestic market integration or even increased fragmentation in China (Poncet, 2003, 2005; World Bank, 2006), which casts doubt on how well the Chinese market is and can be integrated into the global economy compared to what its government promised.

Our paper informs this debate by providing empirical evidence on how regulations combined with regional competition among provinces can be a possible cause for domestic market fragmentation in China. Specifically, we present a setting where it is shown that the imposition of regulation at the local level can be used for protectionist purposes against outside competition and for the creation of intra-national barriers. To the best of our knowledge, this study provides the first micro-level evidence for the presence and patterns of provincial protectionism in China, going beyond the existing analysis at the province or industry level (Young, 2000; Bai et al., 2004; Poncet, 2005; Amiti and Javorcik, 2008; Holz, 2009; Herrmann-Pillatha et al., 2014). We do so through the investigation of a unique case - the public disclosure of "illegal" drug advertisements by provincial Food and Drug Administrations (FDAs) as a penalty for the violation of advertising regulations. We show that the enforcement of ambiguous advertisement rules through selective disclosure is employed to engage in local protectionism, motivated by an institutional setup which aligns the interests of provincial governments and local FDAs. 
A second set of results provides evidence for heterogeneity in the disclosure targets: nonlocal firms from adjacent areas, those from regions with more economic ties to the destination province or with a stronger presence in the drug market, and those with political ties to "allied" provincial governments are less likely to be disclosed. These findings are rationalized by the facts that regional competition in China is shaped by inter-provincial relationships and that local governments may strategically target weaker rivals to avoid future retaliation from strong opponents ("tit-for-tat"). Our results imply that giving provincial governments strong incentives to compete with each other may lead to rent-seeking behavior, echoing the conclusion in Young (2000, p. 1091) that in a partially reformed economy "distortions beget distortions".

This paper is closely linked to the literature on inter-provincial barriers to trade in China. Using primarily regional output and price data, Young (2000) presents various evidence that trade barriers between Chinese provinces increased during the reform period starting from the late 1970s. This finding has however been challenged by Holz (2009) who uses the same data to show that Young's results are not robust and the internal trade barriers are at most on a par with those in a developed economy like the US. Despite this disagreement, both authors seem to support the notion that trade barriers in China are to a large extent created by local "fiefdoms". How these "fiefdoms" actually erect trade barriers is however not investigated, and in the present study we endeavor to provide evidence in this regard. We collect detailed information on those drug manufacturers that have fallen foul of ambiguous advertising rules, which we show can be exploited by local governments to protect local firms from nonlocal competitors. This study thus provides the first direct firm-level evidence for local protectionism and market fragmentation in China, and further characterizes the patterns of discrimination.

Our study also adds to the current debate on "regulatory protectionism" that appears to have emerged as a new "hidden threat" to free trade (e.g. Baldwin, 2000; Chen and Novy, 2011; Bao and Qiu, 2012). In an era where conventional trade barriers have been reduced significantly, protectionism in the guise of technical regulations represents a persistent force against globalization, continuing to shelter domestic producers against foreign competition. In this paper we reveal politico-economic forces as an important cause for such protectionism in the internal market of a developing country.

The remainder of the paper proceeds as follows: Section 2 sets out the institutional background, Section 3 describes the main data, Section 4 contains the empirical results and offers explanations on the patterns found, and Section 5 concludes. 


\section{Institutional Background}

Drugs account for around half of total health spending in China (Sun et al., 2008), three times the share in OECD countries and twice that in other middle-income countries (Meng et al., 2005). It is however widely observed that this large domestic market is severely fragmented by various forms of local protectionism. For example, according to a nationwide survey conducted by a national newspaper Yiyao Jingji Bao (Medicine Economic News) in 2010, over $90 \%$ of corporate respondents reported having been adversely affected by local protectionism in drug procurement where institutional buyers strongly favored local producers. Such experiences are however not unique to institutional procurement, but also prevalent in the retail market. The notorious difficulty of opening cross-regional pharmacy franchises is reported to be mainly caused by local authorities' deliberate over-bureaucratization when dealing with applications from nonlocal retailers (Xinhua News, 2001). Directly relevant to this study, reports of local governments' reluctance to inspect and disclose local producers are also frequently seen in the media (e.g. People's Daily Online, 2013). These phenomena were so epidemic that in 2000 the State FDA issued a prohibition notice to all local FDAs explicitly forbidding any form of protectionist behavior against nonlocal drug sellers, with warnings of severe punishment for local FDA officials upon violation (State FDA, 2000).

The difficulty of promoting sales in a nonlocal market, together with the fierce competition from a large number of small and medium-sized enterprises producing generic over-the-counter drugs (Clark, 2007; Sun et al., 2008), represent major motivations for firms to engage in advertising (Xinhua News, 2004), making the pharmaceuticals industry "one of the highest spenders on advertising in China" (Deloitte, 2011, p. 22). On a practical level, drug producers in China are required to obtain licenses from the respective provinces in order to advertise in any official media outlet in these regions - including television, radio, newspapers, and billboards on commercial vehicles (Deloitte, 2011).

We argue that the institutional setup and the role of FDAs within China's political system provide both scope and incentives for provincial protectionism. For the period under study, the budget and personnel of provincial FDAs were under the control of provincial governments in that the latter not only determined and approved the provincial FDA's costing but also appointed its most senior officials. In addition, provincial governments also exerted indirect control over lower-level FDAs who were subordinate branches of provincial FDAs in a vertically hierarchical structure; see Fig. 1. Consequently, the daily activities of FDAs at all administrative levels within a province, including the monitoring of pharmaceutical firms and their advertising practices, were significantly constrained by 
the provincial government in a direct or indirect way. ${ }^{1}$ By taking hold of the pivotal physical and human resources of local FDAs, the provincial government had great influence over their daily business, enabling it to impose its preferences on their activities.

[Fig. 1 about here]

The influence of local government is rooted in the unique fiscal and political system in China. Introduced in 1994, a new decentralized fiscal system specifies the division of tax revenues between central and local governments, intended to provide tax incentives to provincial governments to push economic development (Qian and Roland, 1998; Cai and Treisman, 2004; Jin et al., 2005). Of all types of tax, value-added tax (VAT) is the major source of fiscal revenue for the government with $75 \%$ of it going to Beijing and $25 \%$ staying at the local level. ${ }^{2}$ Importantly, firms pay VAT to the tax authority of the province where they are located (Ministry of Commerce of the People's Republic of China, 1998), contributing directly to local government budget. A further motivation for protecting local economic interests is from the political side: promotions of local governors within the Communist Party are highly dependent on local economic performance, including gross products and tax revenue (Chen et al., 2005; Li and Zhou, 2005; Jia, 2014). ${ }^{3}$ More formally, a recent theory asserts that China's superior economic growth has been partly driven by the fact that empowered local governors endogenously create regional barriers to benefit their "crony" local entrepreneurs for economic and political rewards (Bai et al., 2014). These forces incentivize local governments to adopt policies which impose, explicitly or implicitly, additional costs on firms from other provinces.

In the case of the drug industry, as the government departments in charge of the implementation of the advertisement regulation, provincial FDAs regularly carry out investigations to spot "illegal" advertisements, send the advertisers a notice of violation, suspend or in case of serious violation cancel their advertising licenses outright, and report the "illegal" cases to other government authorities (e.g. the Bureau for Industry and Commerce) for further administrative and legal actions (fines; suspension or prohibition of sales). Cases of violation are reported by provincial FDAs to the State FDA, then

\footnotetext{
${ }^{1}$ This system was in place between 2000 and 2008, after which it shifted back to a previous setup where lower-level governments, instead of provincial FDAs, had direct control over lower-level FDAs via budget and personnel decisions. However, since this study focuses on provincial-level protectionism, this regime change would not affect the main analysis or implications even if the change happened during the sample period.

${ }^{2}$ Figures taken from Ministry of Finance briefing on "How does VAT work in China?" available at http://www. china.org.cn/english/LivinginChina/202770.htm

${ }^{3}$ On a number of occasions in 2013 China's President Xi Jinping publicly admitted the problems arising from the long-standing practice of basing political appraisal and promotion of government officials on local GDP (Xinhua News, 2013).
} 
publicized on the latter's website, and finally reported in the local and national press. ${ }^{4}$

Importantly, local FDAs are entirely independent in their decision to investigate a specific advertisement and to judge it as "illegal". In contrast to the straightforward case of unlicensed advertising, ${ }^{5}$ what actually constitutes an "illegal drug advertisement" by a licensed firm as stipulated by the State FDA's Standards of Drug Advertisement Censorship is quite ambiguous and clearly open to interpretation. Perhaps the most exceptional rule contained in the Standards stipulates that drug advertisements cannot carry any indication of a positive effect brought about by application of the drug. It is then not surprising that a report by the State FDA in 2004 revealed that strict application of the advertising guidelines would result in $62 \%$ of all advertisements broadcast on television and $95 \%$ of all newspaper advertisements to be classified as "illegal" (Xinhua News, 2004). The blurred boundaries in the definition of "illegality" in practice empower local FDAs with legitimate discretion to selectively shield or punish some producers by using a variant and broad interpretation of the rules. State media further reports estimates that $85 \%$ to 95\% of drug advertisements in Nanjing, the capital city of Jiangsu province, were "illegal" by the national standards, and protection from the local government was blamed for being one of the top reasons why the majority of these advertisements were left undealt with (People's Daily Online, 2005). In a recent survey conducted by a newspaper in Shandong nearly half of the respondents regarded local protectionism as a major obstacle to dealing with illegal advertising (Qingnian Jizhe (Youth Journalists), 2012).

\section{Data}

Our data for disclosed "illegal" drug advertisements (ADVERTS) for 2001-2005 are taken from the Chinese State FDA who publicized on its website the complete lists of "illegal" advertisings merged from provincial FDA reports. ${ }^{6}$ The State FDA website provides details on all firms that "illegally" advertised at least five times in any media outlet. ${ }^{7}$ For each disclosed firm the information provided includes the name of the company and

\footnotetext{
${ }^{4}$ See Appendix for two examples of public disclosure.

${ }^{5}$ Further discrimination could take place in form of failure to reprimand unlicensed local advertisers. We cannot investigate this form of protectionism in our empirical analysis as we do not have information on which firms (licensed or not) advertised and in which provinces.

${ }^{6}$ We do not use data after 2005 as the State FDA's criteria for disclosure changed in 2006 and only the (subjectively) most serious violations of advertising regulations were publicized.

${ }^{7}$ We believe it is unlikely that firms acted strategically and only advertised less than five times to avoid sanction: based on our nationwide sample of 31 provinces, only $9 \%$ of disclosed firms had advertised exactly five times, while the overwhelming majority (91\%) of disclosed firms had advertised many more times: the mean (median) is 37 (15) advertisements and the standard deviation is 60 . We do not have data on the number of advertisements taken out by firms which were not disclosed, but as suggested above fierce competition in a market with many firms and small margins made widespread advertising campaigns a necessity for drug producers.
} 
product, the media outlet, the dates of illegal advertising, the primary reason for "illegality", and the reporting provincial FDA. ${ }^{8}$ On average, nearly 300 firms were disclosed each year as "illegal" advertisers. We do not know the size of the penalties meted out to disclosed firms, except that these were all sent a notice of violation and reported to other government departments for further punishment. Nor do we have information on the decision to inspect a firm, which prevents us from exploiting any systematic patterns of discrimination in this choice. ${ }^{9}$

Our second source of data is the Annual Surveys of Industrial Enterprises (ASIE) from China's National Bureau of Statistics (NBS) which has been used in a number of recent studies (e.g. Cai and Liu, 2009; Hsieh and Klenow, 2009; Brandt et al., 2012; Lu et al., 2013). The surveys include all state-owned firms as well as firms of other ownership types with annual sales above 5 million yuan (around US\$600,000 in year 2000 values). On average, more than 200,000 manufacturing firms were included each year, and these accounted for around $95 \%$ of total Chinese industrial output. For the purpose of our analysis, we restrict the sample to ASIE firms whose primary industry of operation is reported as the pharmaceutical industry, amounting to 20,906 firm-year observations from 7,883 firms for our period of analysis; see Fig. 2 for the geographical distribution of pharmaceutical firms by province.

[Fig. 2 about here]

We match the annualized ADVERTS with the firm-level data from ASIE using firm names. ${ }^{10}$ Appendix Table A1 presents details for the sample and match. About $8 \%$ of all pharmaceutical firms in the ASIE data can be matched to the ADVERTS, constituting the firms which were disclosed as having advertised "illegally". Unmatched firms in ASIE comprise (a) firms which did not advertise, and (b) firms which did advertise but were not disclosed. Unmatched firms in ADVERTS, amounting to 143 (or $18 \%$ of the full set of disclosed firms), represent (a) disclosed firms which were retailers, or (b) private firms which were too small to be included in ASIE.

\footnotetext{
${ }^{8}$ Lack of detailed information about where firms advertised their products prevents us from investigating the media outlet aspect of our disclosure data. Further, this information is missing for many disclosure cases. The limited information provided suggests that among disclosed cases in 31 provinces, $27 \%$ were found on television and in radio broadcasts, $72 \%$ in newspapers, and less than $2 \%$ in other outlets. Focusing on newspapers, it appears that disclosures of nonlocal firms were for advertisements in province- or lower-level outlets (prefecture or city publications), whereas local firms were only disclosed in province-level outlets: this suggests that provincial FDAs exerted additional efforts in searching more intensively for "illegal" advertisements by nonlocal firms.

${ }^{9}$ Similarly, while we exploit information on advertising licenses as discussed below, we do not have data on whether licensed firms actually did advertise their products.

${ }^{10}$ We manually checked every successful match for consistency.
} 
Ideally our estimation strategy would exploit information on who advertised where and when on top of information about disclosure. However, advertising is not observed in our data unless the advertiser was disclosed. As a compromise, two samples of the integrated data are used in our regression analysis. In the main part of the paper we use additional sources of data about advertising licenses issued, taken from the FDA newsletters of those provinces where such data exist. These data are only available for three provinces, namely Jiangsu, Zhejiang and Inner Mongolia, amounting to 2,906 firm-market-year ${ }^{11}$ observations from 569 firms. The former two represent provinces with the largest number of drug producers in the country and fare among China's most developed regions on the eastern seaboard. Inner Mongolia on the other hand is a peripheral province characterized by mining and livestock breeding. The three provinces account for $24 \%$ of nationwide pharmaceutical sales, $18 \%$ of the number of drug producers, and $16 \%$ of employment in the country for the period of 2001-2005. In this part of analysis our results are thus conditional on firms having been granted advertising licenses in the first place.

In auxiliary analysis we introduce additional assumptions that every firm in our full nationwide sample advertises in the above three or in all 31 provinces. These assumptions may sound too strong to be realistic but allow us to expand our sample to check the lower bound of the estimates from our restricted sample and make use of the richer variation in province characteristics. While we isolate some robust effects by countering the new bias introduced by these unrealistic assumptions, the results from the national sample still have to be interpreted with caution. Variables used in our analysis and their data sources (if different from the main data) are described as they are used.

\section{Empirical Analysis}

\subsection{Descriptive results}

We first investigate descriptive patterns across all 31 provinces. Table 1 reports the number of matched firms by disclosure "type". Summed over time, there are less than 40 firms which were only disclosed by their home province's FDA, accounting for less than $4 \%$ of the total 1,059 disclosures. If we include firms which were disclosed both at home and elsewhere this proportion rises to $12 \%$.

[Table 1 about here]

\footnotetext{
${ }^{11}$ The term "market" here refers to one of the three provinces where firms held advertising licenses.
} 
Nevertheless, these patterns may have been driven by regional differences in local FDAs' incentives to disclose nonlocal firms. Specifically, for provinces with a more sizable pharmaceutical sector (and thus more tax revenue), local FDAs are more likely to take discriminatory action to protect local producers. This concern can be addressed by taking out the effect of the size of the provincial pharmaceutical industry. Accordingly, in Fig. 3 we use the vertical axis to represent the proportion of local producers in all disclosed firms, and the horizontal axis to represent the relative size of the provincial industry in the country. If we assume that every firm sell drugs in all 31 provinces, then, in the absence of protectionism, the share of local firms being disclosed should be in line with the relative size of the local pharmaceuticals industry (the $45^{\circ}$ diagonal). However, we find that most of the provinces lie below the $45^{\circ}$ line, indicating a reduced probability of disclosing local firms even after conditioning on the relative size of the province's pharmaceutical industry. A fitted regression line obtains a coefficient of 0.32 , statistically significantly different from 1 at the $5 \%$ level. See Table A2 in the Appendix for the provincial data underlying the graph.

[Fig. 3 about here]

We now restrict our sample to the three provinces for which the data on advertising licenses is available. Table A3 in Appendix provides details on the patterns of disclosure. ${ }^{12}$ The sample is split into disclosed and undisclosed cohorts, which are then further broken down according to whether a firm had been granted a license or not as well as whether the firm was local or not. Two findings emerge. First, over our sample period only a single unlicensed local firm was disclosed (in Jiangsu). This suggests that provincial FDAs may have turned a blind eye on unlicensed local advertisers. Second, among licensed firms, nonlocal firms are systematically more likely to be disclosed than local firms. In all three provinces, around $11 \%$ of nonlocal firms (243 out of 2,178) were disclosed, in stark contrast to a mere $1 \%$ (10 out of 728 ) of local firms. Fig. 4 gives a time-series view of this contrast by market as well as the three-province average. The notable divergence in disclosure patterns of nonlocal versus local firms indicates that nonlocal advertisers appear to be the increasingly preferred targets over time.

[Fig. 4 about here]

\footnotetext{
${ }^{12}$ Table A4 contains the descriptive statistics of the key variables.
} 


\subsection{Regression Results}

\subsubsection{Existence of Local Protectionism}

Given the institutional setup described above, investigations carried out by local FDAs clearly offer room for manipulation and rent-seeking in the determination of "illegal" advertisements. It is thus reasonable to suspect that FDA drug advertising investigations are biased toward protecting local firms. The empirically equivalent question is to investigate whether the probability of a drug producer being publicly disclosed as a punishment for "illegal" advertising is significantly higher for nonlocal producers than for their local counterparts.

The core of our empirical evidence is made up of results from a number of linear probability models testing the hypothesis that nonlocal drug producers are more likely to be publicly disclosed for "illegal" advertising. The baseline results are presented in Table 2. ${ }^{13}$ The sample is comprised of licensed firms in the three provinces since the deliberate targeting of unlicensed firms cannot be verified in the data. ${ }^{14}$ All models presented contain year and firm ownership effects; ${ }^{15}$ standard errors are clustered at the firm-level. The model in column (1) shows that the probability of being disclosed is $10 \%$ higher for nonlocal than for local firms. To further exclude confounding factors at the firm level, in column (2) and onwards we include lagged firm sales (in logs) as a proxy for firm size, and an indicator of whether a firm has previously been disclosed in the same province. ${ }^{16}$ The estimated discrimination effect is now somewhat weaker - around $8 \%$ - but remains substantial. It gets slightly more pronounced in column (3) where we include market dummies to control for unobserved market-specific effects and in column (4) where unobserved market-year specific effects are controlled for. ${ }^{17}$

[Table 2 about here]

The above estimates on the degree of discrimination could be affected by the influence

\footnotetext{
${ }^{13}$ Average marginal effects from probit regressions provide similar patterns (not reported).

${ }^{14}$ Our basic results remain quite robust to the exclusion of Inner Mongolia which has less drug sales than Jiangsu and Zhejiang; see Appendix Table A5.

${ }^{15}$ Regarding ownership effects we find that foreign-invested firms (excluding investments from Hong Kong, Macao, or Taiwan) are significantly less likely to be disclosed than other ownership types. We also investigated the possibility of a link between nonlocal disclosure and ownership type but this did not yield any significant empirical results, a finding in line with Bai et al. (2004) who observe that private firms are no longer at a disadvantage compared to their state-owned counterparts.

${ }^{16}$ The estimates on these two controls are rather stable throughout the study: smaller firms are more likely to be disclosed (with the firm size coefficient being between 1 and 2 percentage points) and prior history explains a significant part (around 30 percentage points) of the probability of disclosure.

${ }^{17}$ Only 16 (out of 569) firms in the sample advertised both locally and nonlocally, making it impossible to obtain precise estimates based on within-firm variation. Therefore we do not include firm-fixed effects in any of our specifications.
} 
of nonlocal sellers in the local market. This is because a stronger presence of nonlocal producers in the local market alone may increase the local government's intention to attack these outsiders. We can control for this possibility explicitly in our data. While we do not know how much (in value terms) nonlocal producers sell in the local market, we have information on the number of nonlocal versus local licensed producers. We suggest that, other things equal, the higher the ratio of the former to the latter, the higher the probability of nonlocal firms being targeted. When this ratio (lagged one year) as well as its interaction with the nonlocal dummy are added in column (5), the discrimination effect is only marginally revised while these additional controls themselves statistically have no effect on the disclosure propensity. ${ }^{18}$

In column (6) we add firm expenditure on advertisements (in logs) as well as its interaction with the nonlocal dummy as controls: more advertising activities may expose a firm to inspections and hence disclosure, a channel which may be more significant for nonlocal firms. Result confirm the influence of advertising activities, but give no indication of a differential effect between local and nonlocal firms, while the discrimination effect remains qualitatively identical. A similar result is obtained in column (7) when we use the advertising intensity, defined as the ratio of advertising expenditure to sales, to control for dependence on advertising, and its interaction with the nonlocal indicator. ${ }^{19}$ In the final column, on top of advertising intensity we further include labor productivity, defined as sales per employee (in logs), and allow it to vary between local and nonlocal firms, to control for the possible effect of firm productivity on disclosure. We find among nonlocal producers that more productive firms are less likely to be disclosed. ${ }^{20}$

With regard to the debate over increasing (Young, 2000) as opposed to ("[i]f anything") decreasing (Holz, 2009) internal barriers to trade for China, our regression models augmented with time-varying "nonlocal" indicators (see Appendix Table A6) suggest the degree of discrimination remained fairly stable over this relatively short time period. The sample also allows us to look at the market-specific discrimination effect by including market-varying nonlocal dummies (see Appendix Table A7). It appears that Inner Mongolia is the most discriminatory province among this trio (though only marginally so compared with Jiangsu) while Zhejiang is the least. ${ }^{21}$

\footnotetext{
${ }^{18}$ Market-year dummies cannot be included in this specification because the ratio measure is defined at the market-year level.

${ }^{19}$ The data for advertisement expenditure is missing in ASIE for 2003, so we lose one year's observations when these advertising measures are included.

${ }^{20}$ The estimates in Table 2 are potentially biased since we only use licensed firms when looking at the discrimination effect. Any potential bias from our setup would arise from differential disclosure patterns (if any) between licensed and unlicensed firms. Since we do not have information on unlicensed advertising firms except for those which were disclosed, it is impossible to evaluate the bias directly. Some informal checks in the Appendix lend support to the sign of our estimates.

${ }^{21}$ This order of ranking can be compared to that based on company managers' perception of local
} 
The above empirical models cannot entirely rule out some biases arising from the endogeneity of nonlocal disclosure, and the results presented do not completely exclude alternative interpretations. For instance, local firms may be intrinsically less likely to be disclosed because of better "local knowledge": local sellers may have a better understanding of how advertisement rules are actually interpreted and implemented at the local level and thus would ensure that their advertisement practices were within the locallydefined realms of the acceptable. A further possible explanation is related to strategic behavior: firms may simply be more aggressive in their advertisements by, for example, including exaggerated claims about the effectiveness of their drugs when competing in nonlocal markets. While both arguments appear to have prima facie validity, the ambiguity of the advertising regulation as well as the stark figures revealed in the media reports quoted above clearly illustrate that any firm, local or nonlocal, could be disclosed as having advertised illegally. Further, after exhaustive background searches we fail to find any evidence to suggest that the effectiveness of drugs - recall that alluding to drug effectiveness in adverts is illegal — is systematically exaggerated in advertisements for products by nonlocal firms.

\subsubsection{Heterogeneities in Local Protectionism}

\section{(A) Inter-Provincial Relationships}

As our discussion suggests, politico-economic competition among provinces is likely to be an institutional source of local protectionism. Specifically, if inter-provincial competition does exist (in the form of, among other characterizations, Li and Zhou (2005) and Bai et al. (2014)), we should observe a pattern of discrimination that varies by region of origin of the advertiser: "illegal" advertising by sellers from economically related provinces are perhaps more likely to be tolerated. Meanwhile, firms from provinces with a more substantial base of pharmaceutical industry are perhaps seen as a threat to local producers and thus more likely to be targeted. As such, we would expect to find a more pronounced discrimination effect for nonlocal firms which are from provinces with fewer economic ties to the location and from those provinces with more significant market presence.

The above reasoning, however, ignores the fact that provincial FDAs may well be

protectionism using data from the World Bank Investment Climate Survey on China in 2004. The Survey was conducted at the company level, but we calculated the province-averages of managers' perception of the severity of local protectionism which ranges from 0 to 4 with 0 indicating not severe at all and 4 very severe. The scores for the three provinces are: Inner Mongolia 0.59, Jiangsu 0.62, and Zhejiang 0.59. Hence Zhejiang appears to be the least discriminating province in both studies. Also note that Jiangsu is the largest market and Inner Mongolia is the smallest market among the three provinces, but because of the rather limited sample this pattern should not be taken as evidence of any definitive relationship between market size and protectionism. For the same reason, nor should this result be seen as contradictory to some theories in regulation economics whereby bigger markets tend to set higher standards and make more rejections when making decisions (e.g. Li, 2001). 
strategic players in a repeated game of symmetric discrimination. A province hostile towards firms from an economically "strong" region is likely to face future retaliation from competing local governments. In anticipation of retaliatory discriminative action, a provincial FDA may proceed in a strategic manner by targeting advertisers from economically "weaker" provinces. Based on these arguments, the net effects of inter-provincial relationship on protectionist discrimination are theoretically unclear.

To throw some empirical light on this question we adopt a measure of economic interdependence between provinces defined as

$$
\text { Province interdependence }_{i, j} \equiv \frac{\text { flow }_{i, j}+\text { flow }_{j, i}}{\text { output }_{i}+\text { output }_{j}}
$$

where the interdependence between provinces $i$ and $j$ depends on the ratio of the sum of bilateral trade flows $\left(\right.$ flow $_{i, j}+$ flow $_{j, i}$ ) to their sum of output $\left(\right.$ output $_{i}+$ output $_{j}$ ). A higher value of this measure implies a higher degree of bilateral dependence between two provinces. We define a province's trade flow with itself as output net of shipments to other provinces and countries following Wei (1996) and Head and Mayer (2000) to account for a province's dependence on itself. Using inter-provincial bilateral trade flow data from the NBS, we find the value of the interdependence measure ranging from $0.02 \%$ to $5 \%$ (with an average of $0.7 \%$ ), and consistently above $50 \%$ (with an average of $75 \%$ ) for a province's self-dependence. ${ }^{22}$ To ease interpretation of the coefficient, we standardize the province interdependence measure so that it has mean of zero and a standard deviation of one. The results are reported in Table 3, where the interaction terms capture the differential effect of the above inter-provincial relationships between two provinces relative to the baseline case of producers advertising in their own market.

[Table 3 about here]

According to the estimates in column (1), a one standard deviation increase in the interdependence measure leads to a 1.3 percentage point drop in the likelihood of disclosure: a closer economic relationship between provinces helps reduce discrimination as provinces tend to be less hostile to producers from "partner" regions. To measure competitive relations between provinces, we use distance between provincial capital cities as well as three other variables - the total number of producers, the gross provincial product, and the total value-added tax (VAT) revenue, all in logs and lagged one year for the pharmaceutical sector in the firm's province of origin — to capture the influence of

\footnotetext{
${ }^{22}$ The bilateral trade flow data for provinces is only available for 2002 , but we believe it is reasonable to assume the stability of the relative ranking of inter-dependence relations between provinces.
} 
differential market presence of a province in this sector. Internal distance of a province is approximated as an average distance between consumers and the center of a disk which is of the same size of the province (see Head and Mayer, 2000). As shown in column (2), distance raises the probability of being disclosed. In columns (3)-(5) our alternative measures of market presence all have significantly negative coefficients, though magnitudes differ substantially. In columns (6)-(8) we weight the three provincial market presence variables by the reciprocal of distance between province pairs to allow for geographical distance to affect inter-provincial competition in tandem with provincial market power. Coefficients remain negative and statistically significant but are now much more in line across specifications. The distance-weighted GDP measure, for instance, implies that if a rival province increases its pharmaceutical output by one percent, its firms will be 3 percent less likely to be disclosed. Considering the average discrimination effect is 8 to 10 percentage points (see Table 2), inter-provincial relationships have a sizable impact and could easily switch the sign of the net effect. Our findings are thus clear: firms are indeed treated differently depending on the type of province they come from, with those from a weaker or less competitive province more likely to be singled out for discrimination.

\section{(B) Political Affiliation}

The second level of heterogeneity we investigate is related to the role of political connections: we want to determine to what extent a firm's affiliation with different levels of government mitigates or exacerbates the effect of provincial protectionism. It has been widely acknowledged that social networks play an important part in countries with weak legal system and contract enforcement (Rauch, 2001). Of all forms of social networks, political connections are believed to be especially important in regulated industries, such as pharmaceuticals, since these are administered by government bureaucrats and close ties with governments may allow firms to exploit regulatory loopholes. This may be particularly salient for non-state enterprises, for whom government institutions may impose additional regulatory red tape (Guriev, 2004) or extralegal fees (Johnson et al., 2000).

Measuring political connections in China is challenging since firms are typically unwilling to reveal this information to outsiders. ${ }^{23}$ In this study, we resort to firms' lishu (literally translated as "subordinate to" or "directly controlled by") affiliation as a proxy for their political connections. A lishu relationship indicates a firm's direct connections

\footnotetext{
${ }^{23}$ Fisman and Wang (2013) exploit the data on publicly listed firms, which are required by law to provide detailed information on senior management, to identify individuals who previously held highlevel government positions. Such information is not available for unlisted firms such as those in our sample. The study by Li et al. (2008) uses Communist Party membership of private firm owners as a measure of political ties with the government and the ruling party. However, party membership information is only collected in bespoke sample surveys created for either of these studies and is not available in our data.
} 
with governments at different levels. It is distinct from ownership and entails both government control as well as subsidies and support. ${ }^{24}$

In our case, both local and nonlocal firms may benefit from such affiliations. On the one hand, if a firm is "local" to a province then political connections may enable it to persuade the local FDA to either let them off the hook when in danger of being disclosed for "illegal" advertising, or to lobby them to single out nonlocal competitors by using a deliberately broader interpretation of the regulations. On the other hand, nonlocal firms may benefit from a political affiliation with their own provincial government because of the environment of inter-provincial competition: being politically connected to a provincial government (or even the central government) could serve as a shelter from discrimination in other regions as local governments may fear that targeting firms directly controlled by other provincial governments would increase the risk of retaliation. The presence and strength of the above benefits, however, may depend on characteristics of the provinces involved and in particular on inter-provincial relationships, which we will subject to empirical validation.

While the data indeed shows variation in political affiliation across firms (see Appendix Table A8 for sample statistics), we are curious to find out if nonlocal producers are more likely disclosed if they have (high-level) political connections. We augment the most comprehensive specification in column (8) of Table 2 by introducing interactions between affiliation type and being a nonlocal firm. The results are presented in Table 4. In column (1), we distinguish three levels of affiliation: affiliations to the central, provincial, and lower-level governments. In column (2) we simplify the affiliation dummy by contrasting provincial government affiliation with all other types. In column (3) we group provincial and central government affiliation together to contrast with other affiliation types. Regardless of which of these classification we adopt none of the affiliation types appear to have a statistically significant differential effect.

[Tables 4 and 5 about here]

\footnotetext{
${ }^{24}$ Tan et al. (2007) describe the lishu affiliation system as a uniquely Chinese institutional framework where the "iron fist" of the planned economy meets the "invisible hand" of the market. Although government interference through lishu declined over time and many private firms in the 2000s opted not to enter into any formal relations, according to Xia et al. (2009, p. 1655), the Chinese "government never clearly or formally state[d] that non-public firms are free from lishu". Based on a small number of empirical studies the economic implications of lishu are somewhat unclear: investigating collectively-owned enterprises during the early 2000s, Xia et al. (2009) find that abandoning lishu with local government enhanced firm performance; Tan et al. (2007), in a study of firms of all ownership types in the late 1990s, report a nonlinear relationship whereby firm productivity declines from top (central) to lower (prefecture-level) lishu affiliation but then dramatically increases for the bottom (township) category; Guariglia and Mateut (forthcoming) find that over the 2000-2007 period higher level lishu affiliation is associated with better access to credit, to the extent that political affiliation can wipe out the historical advantage of state-owned over private firms.
} 
Since these results may be distorted by the interaction of political connections with inter-provincial relationships, we create a full set of interaction terms for affiliation type, inter-provincial relationships and the nonlocal dummy. The estimates for these triple interaction terms are displayed in Table 5. In columns (1)-(5), we only distinguish two affiliation types - affiliation to provincial governments and others. The statistically significant triple interaction terms suggest that the effects of inter-provincial relationship are more pronounced for firms with provincial-level than those with lower affiliations. These estimates are robust to an alternative classification of affiliation in columns (6)(10), where provincial and central government affiliations are again contrasted with other affiliation types. The overall indication of this exercise is that while being away from home exposes a firm to discrimination in other regions, this risk could be offset by good inter-provincial relations and by the home province's market power.

\section{(C) Tax Revenue Incentive}

Another expectation from the earlier discussion is that in provinces with a more substantial share of tax revenue from local drug producers, local governments are more incentivized to protect their local entrepreneurs. We adopt the share of pharmaceutical in manufacturing output (in value terms) as a proxy for a province's fiscal incentive to engage in protection to analyze this channel. A higher value of this share implies a more prominent local pharmaceutical industry, hence a stronger fiscal incentive to safeguard tax revenue. If our hypothesis is correct, we should observe a positive association between this fiscal incentive measure and the propensity of nonlocal firms being disclosed in advertising inspections. We implement this empirical test using an interaction term between the nonlocal dummy and the measure of pharmaceutical share in total manufacturing output. A problem with the three-province sample for this test is the lack of cross-province variation for our fiscal incentive measure. We therefore return to the full sample of 31 provinces, but at the price of having to rely on the strong assumption that every firm advertises in all provinces. We should expect a downward biased, likely insignificant, average discrimination effect because of the vastly overstated number of nonlocal firms engaging in advertising. However, since we are not aware of any compelling evidence for whether and how this bias is correlated with province fiscal incentive, it is worth checking the differential effect. The results are contained in Table 6.

[Table 6 about here]

In the baseline model in column (1), the discrimination effect is significantly positive but as expected economically very small. The coefficients on pharmaceutical share in GDP and on the interaction term suggest that a larger local pharmaceutical industry 
leads to a higher propensity for the local FDA to (i) disclose any advertisers, and (ii) to disproportionately disclose nonlocal advertisers. The "tax revenue incentive" effect is estimated to be $10-15 \%$. Given that the pharmaceutical share measure ranges from 0 to 1 , the estimated effect implies that a 10 percentage point increase in the pharmaceutical share leads to a 1-1.5 percentage point increase in the disclosure propensity, which is a sizable impact given that the average effect is underestimated in these models. Overall, these results provide evidence for a "tax revenue motive" underlying local protectionism. ${ }^{25}$

\section{Concluding Remarks}

This study offers direct micro-level evidence for the existence and patterns of provincial protectionism in China. We show that drug advertising regulations and inspections are used as a protectionist tool by provincial administrations to shelter local firms from extra-provincial competition. In addition, the actual pattern of protectionism is rather heterogeneous: while firms from "weaker" provinces in terms of pharmaceutical industry prowess are preferred targets, firms from economic "partner" provinces experience comparatively less discrimination. These findings are consistent with the observations and theories on the politico-economic competition among regions in China, and the overall picture we depict accords closely with the recent characterization of China's growth model as "crony capitalism" with fierce inter-regional competition (Bai et al., 2014).

Our findings point to some specific areas where efforts could be made to reduce internal trade barriers in China. First, tighter screening of the local application of national regulations may be useful to reduce the scope for rent-seeking behavior on behalf of local authorities. Second, political ties between local regulatory authorities and local governments should be reduced or cut to counteract the resulting incentives for discriminatory behavior in the narrow interest of local governments and producers. Third, while polit-

\footnotetext{
${ }^{25} \mathrm{~A}$ caveat regarding the results based on the full 31 province sample is that the strong assumption of every firm advertising in every provinces leads to bias in the key parameters of interest. This issue is difficult to tackle satisfactorily given the data at our disposal. However, a "permutation exercise" may be helpful to check whether the assumption itself could be driving some of the key relations we find in the data. Specifically, by repeatedly drawing a subset of provinces from the full 31 province sample, we artificially expand the variation of province characteristics, which then allows us to investigate whether those characteristics identified as crucial in our analysis are sensitive to the particular sample of provinces selected. While we know that the disclosure propensity for nonlocal firms is significantly downward biased because of the assumption that all firms advertise in all provinces, our test of the "tax revenue incentive" hypothesis in these permutations would be biased only if the underestimated disclosure propensity were to differ systematically with different levels of pharmaceutical-to-total manufacturing output across provinces. The results of our permutation exercise indicate that a $10 \%$ increase in the share of pharmaceuticals in manufacturing output is associated with a $0.4 \%$ increase in the estimated discrimination effect, thus broadly supporting the finding of the fiscal incentive motive. More details on this exercise are available from the corresponding author upon request.
} 
ical affiliations with regional governments may be beneficial to a firm's business in the local market, it may be detrimental to its sales in other regions. This calls for a further de-politicization of the economy - the withdrawal of governmental power from the realm of the market, a pressing task in the gradual economic reform in China.

Our study suffers from several data limitations. First, we are unable to identify licensed firms except in a small subset of provinces, which limits our ability to link the protectionism pattern to the characteristics of the implementing provinces. Second, since firm sales data are not available by province, we cannot quantify the effect of discrimination on firm performance in each market. We believe, however, the makeup of our three-province sample, including advanced and backward provinces, suggests some representativeness for the country at large.

This research has a potential for some follow-up work to assess the welfare impact of local protectionism. While a growing literature shows that excessive regulations cause sizable welfare losses in developed economies (see e.g. Jones et al. (2009) for the US), a possible extension of this study is to evaluate the net welfare effect of the provincial competition in China.

\section{References}

Amiti, Mary and Beata Smarzynska Javorcik (2008), "Trade Costs and Location of Foreign Firms in China," Journal of Development Economics, 85(1-2), 129-149.

Atkin, David and Dave Donaldson (2015), "Who's Getting Globalized? The Size and Nature of Intranational Trade Costs," NBER Working Paper No. 21439.

Bai, Chong-En, Yingjuan Du, Zhigang Tao, and Yueting Sarah Tong (2004), "Local Protectionism and Regional Specialization: Evidence from China's Industries," Journal of International Economics, 63(2), 397-417.

Bai, Chong-En, Chang-Tai Hsieh, and Zheng Song (2014), "Crony Capitalism with Chinese Characteristics," Chicago Booth School of Business, unpublished mimeo.

Baldwin, Richard E. (2000), "Regulatory Protectionism, Developing Nations and a TwoTier World Trade System," in Brookings Trade Forum 2000, ed. by S. Collins and D. Rodrik, Washington D.C.: The Brookings Institution Press, 237-293.

Bao, Xiaohua and Larry D. Qiu (2012), "How do Technical Barriers to Trade Influence Trade?" Review of International Economics, 20(4), 691-706.

Brandt, Loren, Johannes Van Biesebroeck, and Yifan Zhang (2012), "Creative Accounting or Creative Destruction? Firm-level Productivity Growth in Chinese Manufacturing," 
Journal of Development Economics, 97(2), 339-351.

Cai, Hongbin and Qiao Liu (2009), "Competition and Corporate Tax Avoidance: Evidence from Chinese Industrial Firms," Economic Journal, 119(537), 764-795.

Cai, Hongbin and Daniel Treisman (2004), "State Corroding Federalism," Journal of Public Economics, 88(3-4), 819-843.

Chen, Natalie and Dennis Novy (2011), "Gravity, Trade Integration, and Heterogeneity across Industries," Journal of International Economics, 85(2), 206-221.

Chen, Ye, Hongbin Li, and Li-An Zhou (2005), "Relative Performance Evaluation and the Turnover of Provincial Leaders in China," Economics Letters, 88(3), 421-425.

Clark, Todd D. (2007), PharmaHandbook: A Guide to the International Pharmaceutical Industry, Insight Consulting Inc., 5 ed.

Coşar, A. Kerem and Pablo D. Fajgelbaum (forthcoming), "Internal Geography, International Trade, and Regional Specialization," American Economic Journal: Microeconomics.

Coughlin, Cletus C. and Dennis Novy (2013), "Is the International Border Effect Larger than the Domestic Border Effect? Evidence from US Trade," CESifo Economic Studies, 59(2), 249-276.

Deloitte (2011), "The Next Phase: Opportunities in China's Pharmaceutical Market," National Industry Practice Report.

Fisman, Ray and Yongxiang Wang (2013), "The Mortality Cost of Political Connections," Unpublished mimeo, presented at the NBER Chinese Economy Working Group.

Guariglia, Alessandra and Simona Mateut (forthcoming), "External Finance and Trade Credit Extension in China: Does Political Affiliation Make a Difference?" European Journal of Finance.

Guriev, Sergei (2004), "Red Tape and Corruption," Journal of Development Economics, $73(2), 489-504$.

Head, Keith and Thierry Mayer (2000), "Non-Europe: The Magnitude and Causes of Market Fragmentation in the EU," Review of World Economics, 136(2), 284-314.

Herrmann-Pillatha, Carsten, Alexander Libmana, and Xiaofan Yu (2014), "Economic Integration in China: Politics and Culture," Journal of Comparative Economics, 42(2), 470-492.

Holz, Carsten A. (2009), "No Razor's Edge: Reexamining Alwyn Young's Evidence for Increasing Interprovincial Trade Barriers in China," Review of Economics and Statistics, 91(3), 599-616.

Hsieh, Chang-Tai and Peter J. Klenow (2009), "Misallocation and Manufacturing TFP 
in China and India," Quarterly Journal of Economics, 124(4), 1403-1448.

Jia, Ruixue (2014), "Pollution for Promotion," University of California, San Diego, unpublished mimeo.

Jin, Hehui, Yingyi Qian, and Barry R. Weingast (2005), "Regional Decentralization and Fiscal Incentives: Federalism, Chinese Style," Journal of Public Economics, 89(9-10), $1719-1742$.

Johnson, Simon, Daniel Kaufmann, John McMillan, and Christopher Woodruff (2000), "Why do Firms Hide? Bribes and Unofficial Activity after Communism," Journal of Public Economics, 76(3), 495-520.

Jones, Keithly G., Agapi Somwaru, and James B. Whitaker (2009), "Country of Origin Labeling: Evaluating the Impacts on U.S. and World Markets," Agricultural and Resource Economics Review, 38(3), 397-405.

Li, Hao (2001), "A Theory of Conservatism," Journal of Political Economy, 109(3), 617636.

Li, Hongbin, Lingsheng Meng, Qian Wang, and Li-An Zhou (2008), "Political Connections, Financing and Firm Performance: Evidence from Chinese Private Firms," Journal of Development Economics, 87(2), 283-299.

Li, Hongbin and Li-An Zhou (2005), "Political Turnover and Economic Performance: The Incentive Role of Personnel Control in China," Journal of Public Economics, 89(9-10), 1743-1762.

Lu, Yi, Ivan P. L. Png, and Zhigang Tao (2013), "Do Institutions Not Matter in China? Evidence from Manufacturing Enterprises," Journal of Comparative Economics, 41(1), $74-90$.

Meng, Qingyue, Gang Cheng, Lynn Silver, Xiaojie Sun, Clas Rehnberg, and Göran Tomson (2005), "The Impact of China's Retail Drug Price Control Policy on Hospital Expenditures: A Case Study in Two Shandong Hospitals," Health Policy and Planning, 20(3), 185-196.

Ministry of Commerce of the People's Republic of China (1998), "Provisional Regulations of the People's Republic of China on Value-Added Tax," http://english.mofcom . gov.cn/article/lawsdata/chineselaw/200411/20041100311038.shtml.

People's Daily Online (2005), "Xiang Weifa Xujia Guanggao Shuo Bu (Saying No to Illegal and Fake Advertisements)," http://www.people.com.cn/GB/guandian/183/ 6103/6104/2604835.html.

(2013), "Difang Baohu Rang Xujia Yiliao Guanggao Wangkai Yimian (Protectionism Leaves the Door Wide Open to Adverts for Fake Local Drugs)," http: //health.people.com.cn/n/2013/0528/c14739-21638110.html. 
Poncet, Sandra (2003), "Measuring Chinese Domestic and International Integration," China Economic Review, 14(1), 1-21.

(2005), "A Fragmented China: Measure and Determinants of Chinese Domestic Market Disintegration," Review of International Economics, 13(3), 409-439.

Qian, Yingyi and Gerard Roland (1998), "Federalism and the Soft Budget Constraint," American Economic Review, 88(5), 1143-1162.

Qingnian Jizhe (Youth Journalists) (2012), "Zenyang Kan Meiti Kandeng Xujia Weifa Guanggao (Views on False and Illegal Advertisements in the Media," http://www. qnjz.com/meiyuediaocha/201205/t20120502_7071338.htm.

Ramondo, Natalia, Andrés Rodríguez-Clare, and Milagro Saborío-Rodríguez (2014), "Trade, Domestic Frictions, and Scale Effects," NBER Working Paper No. 18532.

Rauch, James E. (2001), "Business and Social Networks in International Trade," Journal of Economic Literature, 39(4), 1177-1203.

State FDA (2000), "Guanyu Bude Yi Renhe Mingyi Xianzhi Huo Paichi Waibu Shengchan De Yaopin Jinru Bendiqu Xiaoshou De Tongzhi (Notice on the Ban of Any Form of Restrictions on or Prevention of the Sale of Nonlocally-Produced Drugs)," http: //www.gov.cn/gongbao/content/2001/content_60840.htm.

Sun, Qiang, Michael A. Santoro, Qingyue Meng, Caitlin Liu, and Karen Eggleston (2008), "Pharmaceutical Policy In China," Health Affairs, 27(4), 1042-1050.

Tan, Justin, Shaomin Li, and Jun Xia (2007), "When Iron Fist, Visible Hand, and Invisible Hand Meet: Firm-level Effects of Varying Institutional Environments in China," Journal of Business Research, 60(7), 786-794.

Wei, Shang-Jin (1996), "Intra-National versus International Trade: How Stubborn are Nations in Global Integration?" NBER Working Paper No. 5531.

World Bank (2006), China: Governance, Investment Climate, and Harmonious Society, Washington: World Bank.

Xia, Jun, Shaomin Li, and Cheryl Long (2009), "The Transformation of Collectively Owned Enterprises and Its Outcomes in China, 2001-05," World Development, 37(10), $1651-1662$.

Xinhua News (2001), "Yaojianju Fuzeren Tongchi Difang Baohu 'Yinyang Lian' (FDA Official Criticises the 'Two Faces' of Local Protectionism)," http://finance.sina. com.cn/g/20010831/102614.html.

(2004), "Bufen Baozhi Yaopin Guanggao Weifa Fabulü Gaoda 95\% (The Proportion of Illegal Drug Advertisements in Some Newspapers is as High as 95\%)," http://news. xinhuanet.com/health/2005-01/13/content_2452992.htm.

(2013), "Buyi GDP Lun Yingxiong Dang Chengwei Fazhan Fangshi De Zijue 
(GDP Should No Longer Be Used as the Only Criterion for Economic Development)," http://news.xinhuanet.com/politics/2013-11/09/c_118070300.htm.

Young, Alwyn (2000), "The Razor's Edge: Distortions and Incremental Reform in the People's Republic of China," Quarterly Journal of Economics, 115(4), 1091-1135. 


\section{Tables}

Table 1. Numbers of Firms by Disclosure Type - 31 Provinces

\begin{tabular}{lrrrrr}
\hline & & \multicolumn{4}{c}{ Disclosed firms } \\
\cline { 3 - 5 } Year & Undisclosed \\
\cline { 3 - 6 } & firms & only in & $\begin{array}{r}\text { only in } \\
\text { home province }\end{array}$ & in both home and \\
other provinces & other provinces & Total \\
\hline 2001 & 3,349 & 0 & 135 & 2 & 3,486 \\
2002 & 3,364 & 23 & 283 & 10 & 3,680 \\
2003 & 3,900 & 3 & 145 & 14 & 4,062 \\
2004 & 4,535 & 4 & 227 & 36 & 4,709 \\
2005 & 4,699 & 35 & 606 & 68 & 4,969 \\
Total & 7,770 & 745 & 3,883 \\
\hline
\end{tabular}

Note. We report the number of firms in all rows. Repeated disclosure for illegal advertising accounts for the discrepancy between the totals and column sums for disclosed firms, the unbalanced nature of the panel for the same discrepancy in the undisclosed firms. 


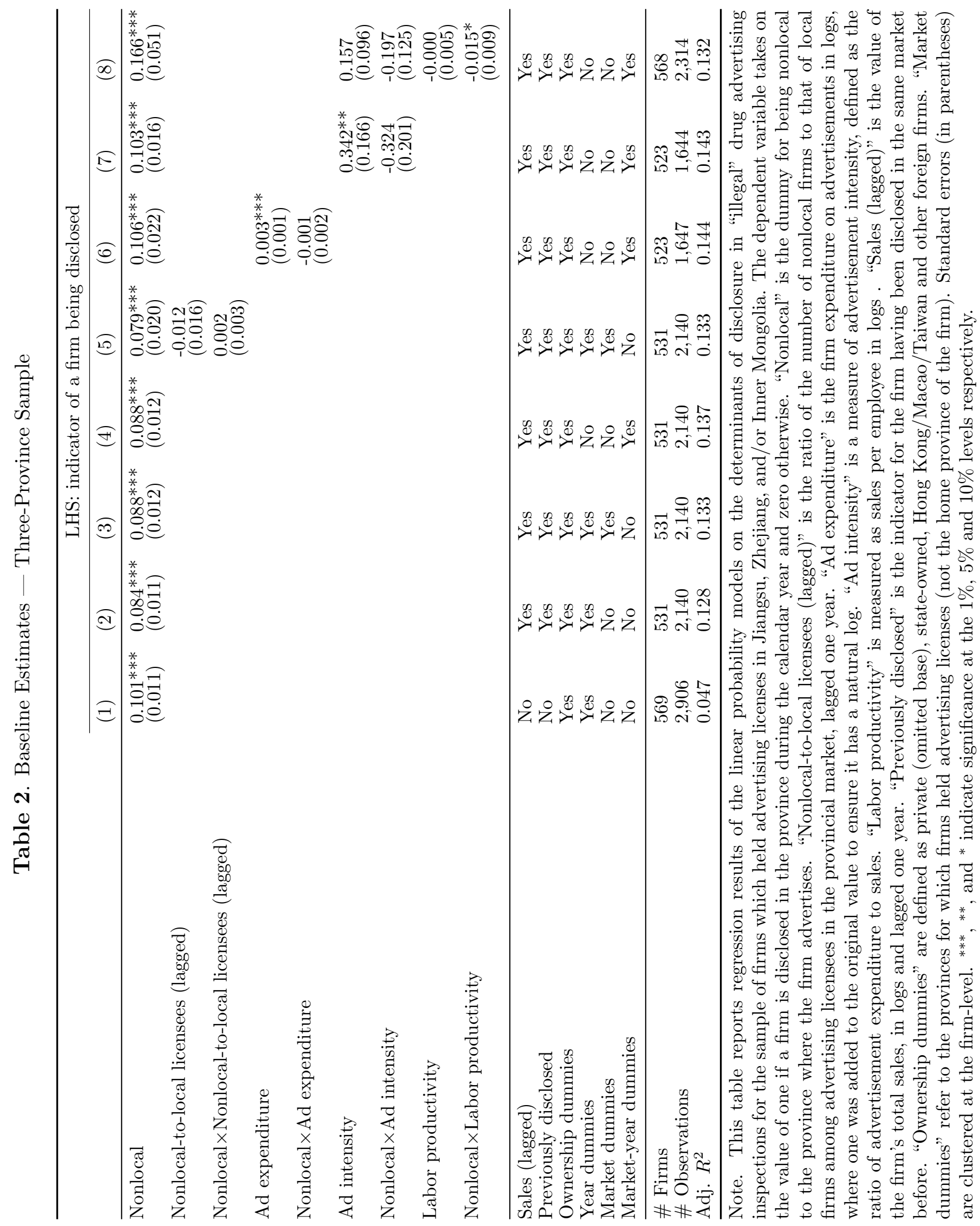




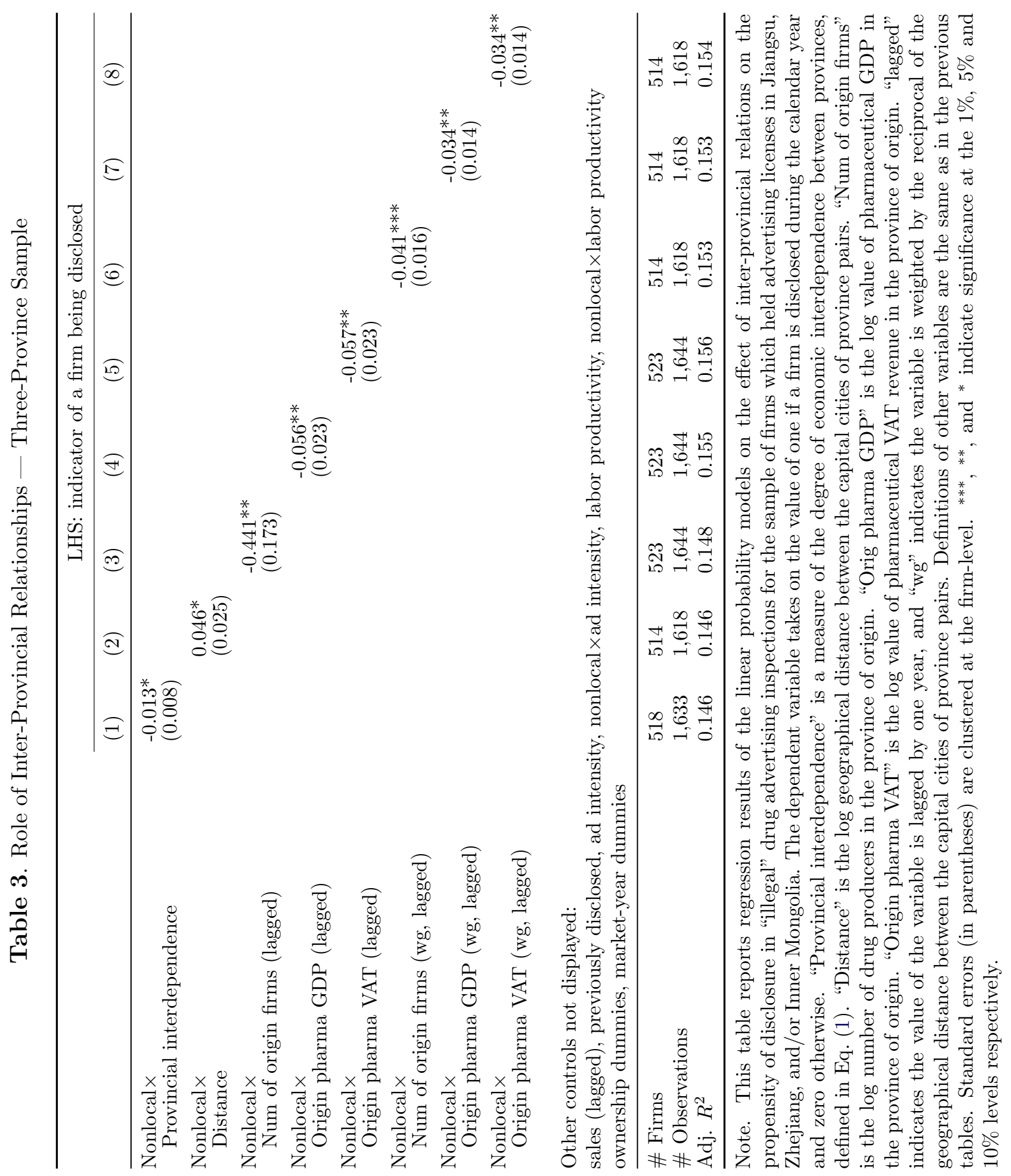


Table 4. Role of Political Affiliation — Three-Province Sample

\begin{tabular}{|c|c|c|c|}
\hline & \multicolumn{3}{|c|}{ LHS: indicator of a firm being disclosed } \\
\hline & $(1)$ & $(2)$ & $(3)$ \\
\hline Nonlocal & $\begin{array}{l}0.206^{* * *} \\
(0.075)\end{array}$ & $\begin{array}{l}0.219^{* * *} \\
(0.070)\end{array}$ & $\begin{array}{l}0.220^{* * *} \\
(0.071)\end{array}$ \\
\hline Lower-level affiliation & \multicolumn{3}{|l|}{$\begin{array}{l}0.015 \\
(0.014)\end{array}$} \\
\hline Provincial affiliation & $\begin{array}{l}0.013 \\
(0.036)\end{array}$ & \multicolumn{2}{|l|}{$\begin{array}{l}-0.004 \\
(0.032)\end{array}$} \\
\hline Central affiliation & \multicolumn{3}{|l|}{$\begin{array}{l}0.039 \\
(0.049)\end{array}$} \\
\hline Nonlocal $\times$ Lower-level affiliation & \multicolumn{3}{|l|}{$\begin{array}{l}0.015 \\
(0.033)\end{array}$} \\
\hline Nonlocal $\times$ Provincial affiliation & $\begin{array}{l}0.070 \\
(0.055)\end{array}$ & \multicolumn{2}{|l|}{$\begin{array}{l}0.056 \\
(0.047)\end{array}$} \\
\hline Nonlocal $\times$ Central affiliation & \multicolumn{3}{|l|}{$\begin{array}{l}0.103 \\
(0.106)\end{array}$} \\
\hline$($ Provincial + central $)$ affiliation & & & $\begin{array}{l}0.004 \\
(0.033)\end{array}$ \\
\hline Nonlocal $\times($ Provincial + central $)$ affiliation & & & $\begin{array}{l}0.059 \\
(0.043)\end{array}$ \\
\hline \multicolumn{4}{|c|}{$\begin{array}{l}\text { Other controls not displayed: } \\
\text { sales (lagged), previously disclosed, ad intensity, nonlocal×ad intensity, } \\
\text { labor productivity, nonlocal×labor productivity, ownership dummies, market-year dummies }\end{array}$} \\
\hline \# Firms & 523 & 523 & 523 \\
\hline \# Observations & 1,644 & 1,644 & 1,644 \\
\hline Adj. $R^{2}$ & 0.147 & 0.146 & 0.148 \\
\hline
\end{tabular}

Note. This table reports regression results of the linear probability models on the interacted effect of political affiliation and inter-provincial relations on the propensity of disclosure in "illegal" drug advertising inspections for the sample of firms which held advertising licenses in Jiangsu, Zhejiang, and/or Inner Mongolia. The dependent variable takes on the value of one if a firm is disclosed in the province during the calendar year and zero otherwise. "Provincial affiliation" is a dummy which takes on the value of one for provincial government affiliation and zero otherwise. "Central affiliation" is a dummy which takes on the value of one for central government affiliation and zero otherwise. "Lower affiliation" is a dummy which takes on the value of one for below-province level government affiliation and zero otherwise. "(Provincial + central) affiliation" is a dummy which takes on the value of one for provincial or central government affiliation and zero otherwise. Definitions of all other variables are the same as in the previous tables. Standard errors (in parentheses) are clustered at the firm-level. ${ }^{* * *},{ }^{* *}$, and ${ }^{*}$ indicate significance at the $1 \%, 5 \%$ and $10 \%$ levels respectively. 


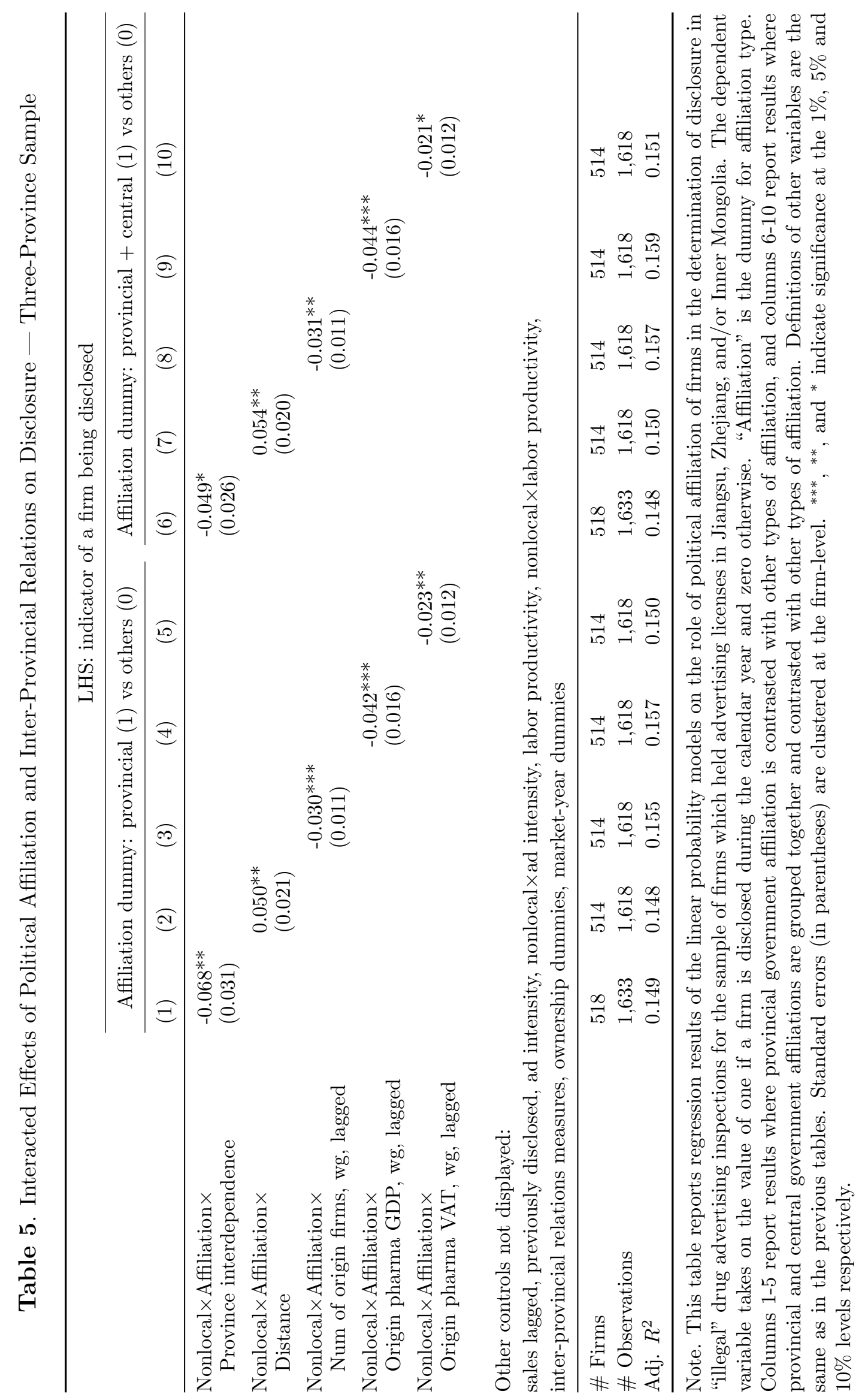


Table 6. Tax Revenue Incentive and Discriminative Disclosure - 31-Province Sample

\begin{tabular}{llllll}
\hline & \multicolumn{3}{c}{ LHS: indicator of a firm being disclosed } \\
\cline { 2 - 5 } & $(1)$ & $(2)$ & $(3)$ & $(4)$ & $(5)$ \\
\hline Nonlocal & $0.002^{* *}$ & -0.002 & -0.002 & -0.003 & -0.008 \\
& $(0.001)$ & $(0.002)$ & $(0.002)$ & $(0.002)$ & $(0.005)$ \\
Share of pharma GDP & & $0.088^{* * *}$ & $0.093^{* *}$ & $0.095^{* *}$ & $0.090^{* *}$ \\
& & $(0.030)$ & $(0.040)$ & $(0.040)$ & $(0.040)$ \\
Nonlocal*(Share of pharma GDP) & & $0.109^{* *}$ & $0.139^{* *}$ & $0.140^{* *}$ & $0.145^{* *}$ \\
& & $(0.044)$ & $(0.059)$ & $(0.060)$ & $(0.060)$ \\
\hline Ad expenditure & No & No & Yes & No & No \\
Nonlocal×Ad expenditure & No & No & Yes & No & No \\
Ad intensity & No & No & No & Yes & Yes \\
Nonlocall×Ad intensity & No & No & No & Yes & Yes \\
Labor productivity & No & No & No & No & Yes \\
Nonlocall $\times$ Labor productivity & No & No & No & No & Yes \\
Sales (lagged) & Yes & Yes & Yes & Yes & Yes \\
Previously disclosed & Yes & Yes & Yes & Yes & Yes \\
Ownership dummies & Yes & Yes & Yes & Yes & Yes \\
Market-year dummies & Yes & Yes & Yes & Yes & Yes \\
\hline \# Firms & 5,531 & 5,531 & 5,353 & 5,311 & 5,310 \\
$\#$ Observations & 388,306 & 388,306 & 298,313 & 296,391 & 296,329 \\
Adj. $R^{2}$ & 0.066 & 0.068 & 0.074 & 0.074 & 0.074 \\
\hline Note Thy
\end{tabular}

Note. This table reports regression results of the linear probability models on the determinants of disclosure in "illegal" drug advertising inspections for the sample of all firms in 31 provinces under the assumption that every firm advertises in all provinces. The dependent variable takes on the value of one if a firm is disclosed in the province during the calendar year and zero otherwise. Definitions of the other variables are the same as in the previous tables, except the introduction of the interactions between year dummies (with 2001 as the omitted base) and the nonlocal dummy. Standard errors (in parentheses) are clustered at the firm-level. ${ }^{* * *},{ }^{* *}$, and ${ }^{*}$ indicate significance at the $1 \%, 5 \%$ and $10 \%$ levels respectively. 


\section{Figures}

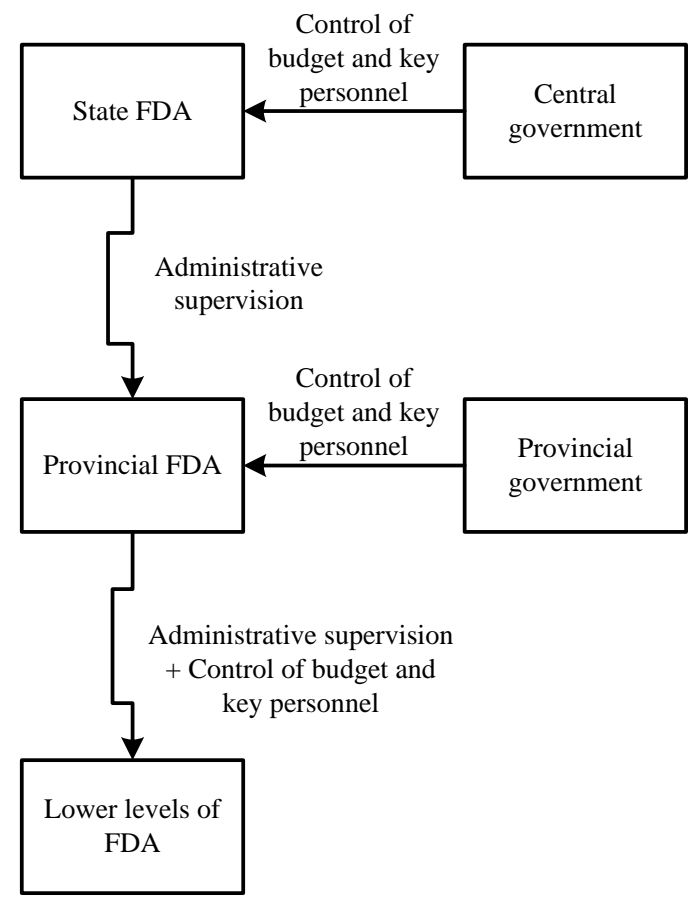

Fig. 1. The Relationships between FDAs and Governments in China, 2000-2008. This chart shows the relations between FDAs of different levels as well their relations with governments of different levels. This structure was in place between 2000 and 2008 and indicates the channels through which provincial governments could exert influence over local FDAs at both the provincial and lower levels. 


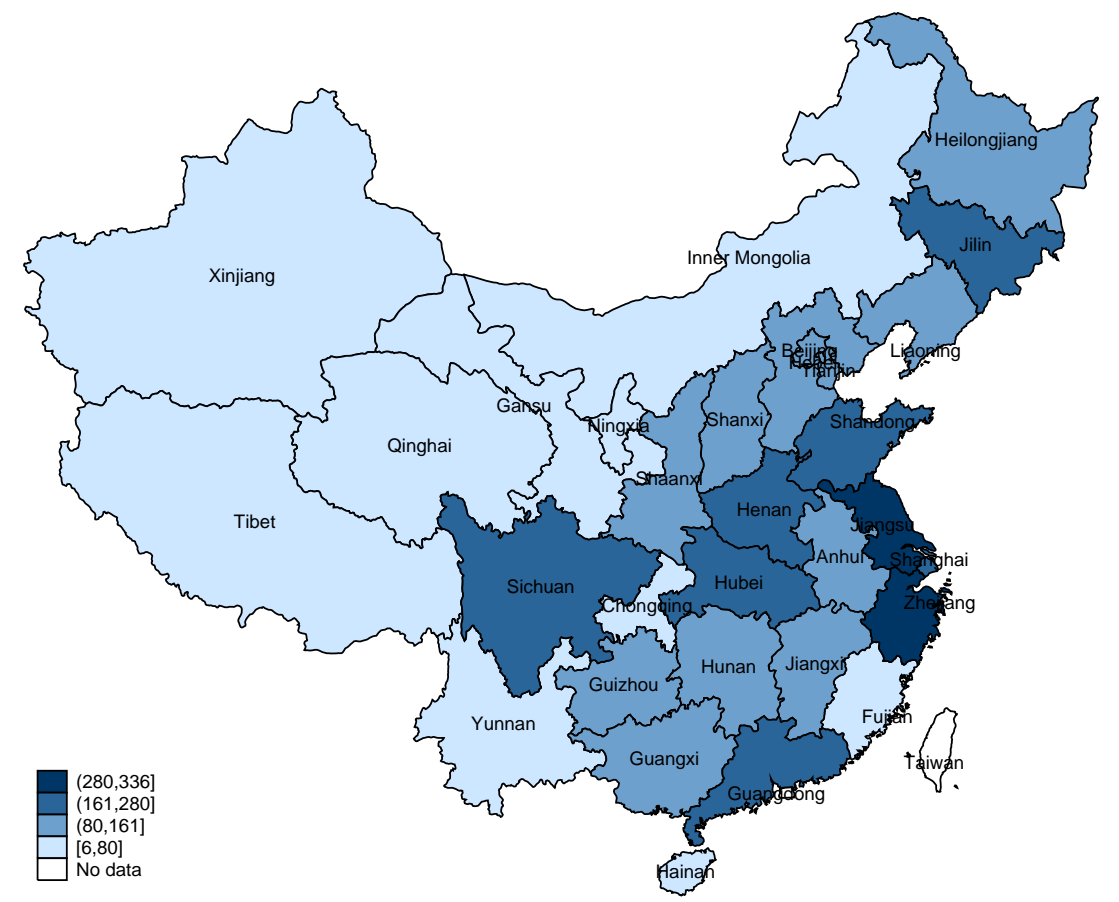

Fig. 2. Numbers of Drug Producers by Province. This map plots the number of drug firms (defined as those whose primary industry of operation is reported as the pharmaceutical industry in the ASIE database) by province in 2003. 


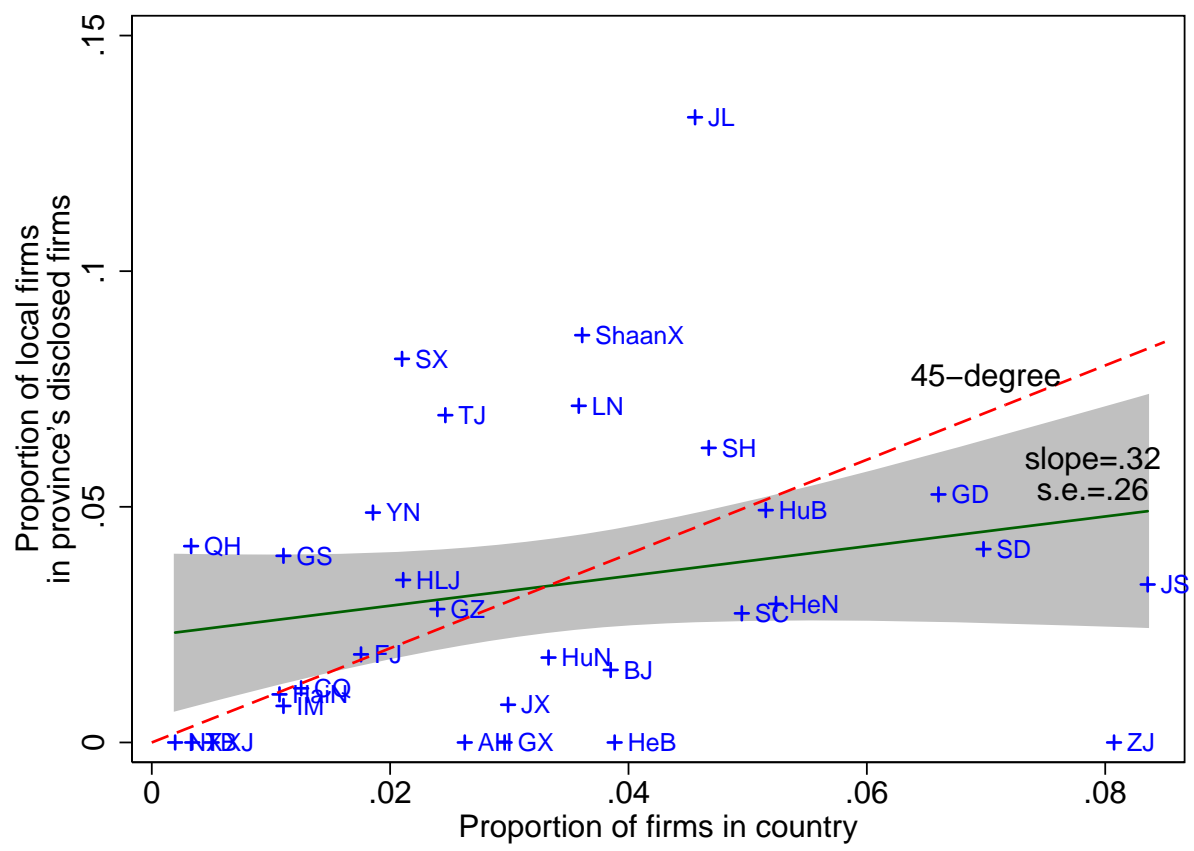

Fig. 3. Proportions of Local Firms Disclosed - 31-Province Sample. This figure shows the proportion of local firms disclosed in each province across all years (2001-2005) conditional on the relative size of the province's pharmaceutical industry in the country (measured by the proportion of drug firms in the country). The ' + ' signs represent provinces, the solid line represents the fitted line from an OLS regression, the dashed line is the $45^{\circ}$ diagonal, and the shaded area indicates the $90 \%$ confidence interval of the OLS regression line. 


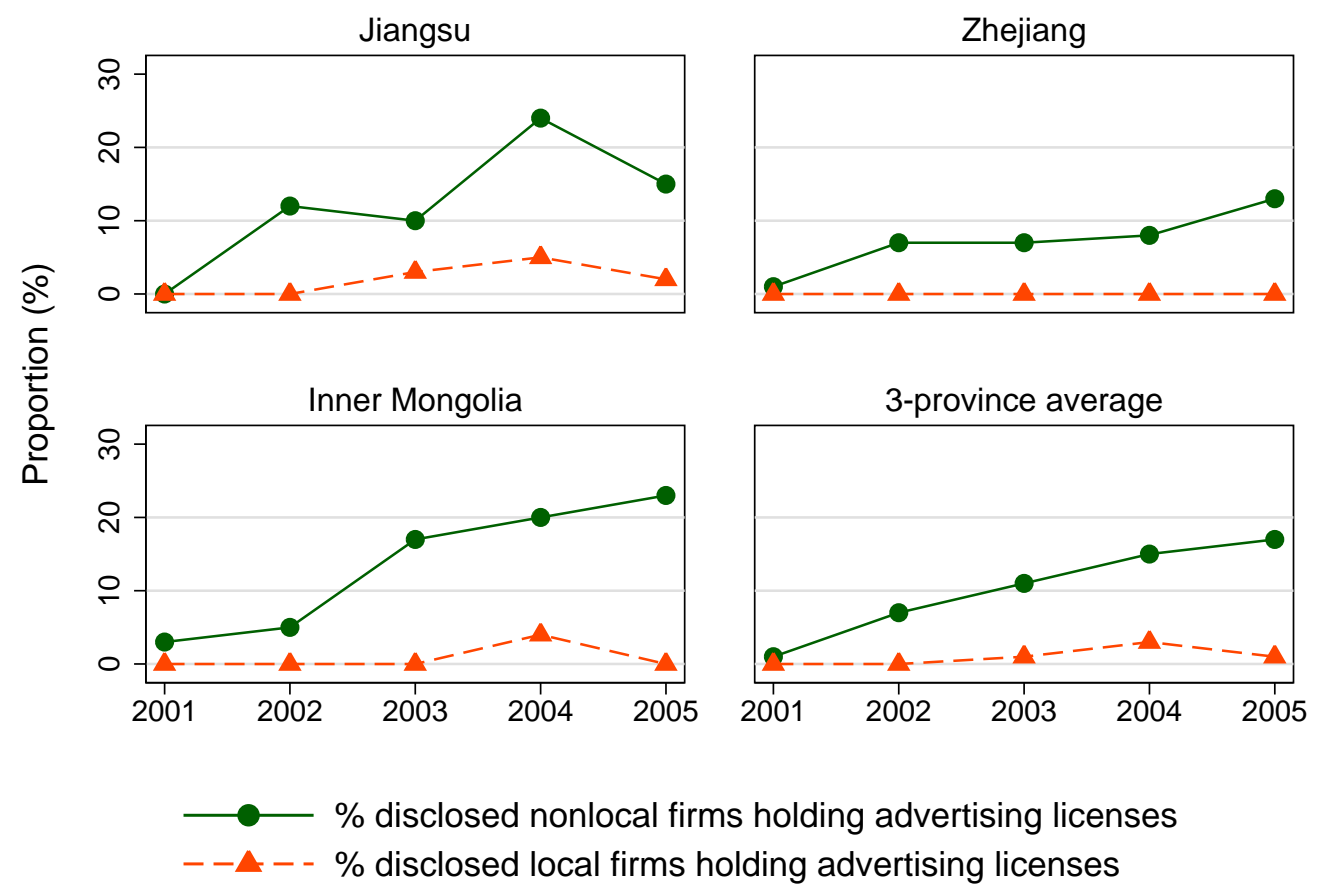

Fig. 4. Proportions of Disclosed Firms for Licensed Advertisers -

Three-Province Sample. This figure shows the proportions of licensed nonlocal firms which were disclosed as "illegal" advertisers and the proportions of licensed local firms which were disclosed as "illegal" advertisers for the three provinces of Jiangsu, Zhejiang and Inner Mongolia as well as the 3-province averages in each year from 2001 to 2005. 


\section{Appendix - not intended for publication}

\section{Two Examples of Public Disclosure}

In 2007 "Fei Xiao Tong Chang" cough syrup was disclosed for exaggerated advertisements in the city of Suzhou. The Bureau for Industry and Commerce in Suzhou forced its manufacturer to stop the advertisement immediately as well as to pay a fine of 7,500 yuan (at the time around US\$1,000); see http://www.bsqgsj.gov.cn/baweb/show/ shiju/bawebFile/3411.html. In a more serious case in 2013, an advertiser in Zhejiang Province was fined 122,679 yuan (at the time around US\$20,000) for "misleading content in advertisement" of its drug to treat arthritis-related diseases; see http://news . xinhuanet.com/health/2013-04/25/c_124630444.htm. It should be noted that fines for illegal advertisement in China never appear to have been set under a nationwide standard and that in practice different local FDAs and related authorities enjoy a great degree of discretion when it comes to specific cases; see, for instance, the recent rules set by Sichuan Province, http://opinion.chengdu.cn/topic/2014-10/14/content_ 1563916 . htm?node=12023.

\section{Additional Tables and Figures}

Table A1. Numbers of Firms - 31-Province Sample

\begin{tabular}{lrrr}
\hline Year & ASIE & ADVERTS & $\begin{array}{r}\text { Matched } \\
\text { ASIE-ADVERTS }\end{array}$ \\
\hline 2001 & 3,486 & 175 & 137 \\
2002 & 3,680 & 449 & 316 \\
2003 & 4,062 & 221 & 162 \\
2004 & 4,709 & 214 & 174 \\
2005 & 4,969 & 328 & 270 \\
Total & 7,883 & 796 & 653 \\
\hline
\end{tabular}


Table A2. Numbers of Local and Nonlocal Firms Disclosed for "Illegal" Advertising - 31-Province Sample

\begin{tabular}{|c|c|c|c|c|c|c|c|}
\hline \multirow[b]{2}{*}{ Province } & \multicolumn{3}{|c|}{ (1) } & \multirow{2}{*}{$\begin{array}{r}(2) \\
\% \text { local } \\
\text { firms in } \\
\text { disclosed }\end{array}$} & \multirow{2}{*}{$\begin{array}{r}(3) \\
\% \text { province's } \\
\text { firms in } \\
\text { country }\end{array}$} & \multirow{2}{*}{$\begin{array}{l}\text { (4) } \\
\text { \% province's } \\
\text { employment } \\
\text { in country }\end{array}$} & \multirow[b]{2}{*}{$\begin{array}{r}\text { Difference } \\
(2)-(3)\end{array}$} \\
\hline & Local & $\begin{array}{l}\text { Non- } \\
\text { local }\end{array}$ & All & & & & \\
\hline Ningxia & 0 & 28 & 28 & 0.00 & 0.20 & 0.28 & -0.20 \\
\hline Qinghai & 2 & 46 & 48 & 4.17 & 0.33 & 0.29 & 3.84 \\
\hline Tibet & 0 & 5 & 5 & 0.00 & 0.34 & 0.13 & -0.34 \\
\hline Xinjiang & 0 & 83 & 83 & 0.00 & 0.50 & 0.26 & -0.50 \\
\hline Hainan & 1 & 97 & 98 & 1.02 & 1.07 & 0.51 & -0.05 \\
\hline Gansu & 4 & 97 & 101 & 3.96 & 1.10 & 1.03 & 2.86 \\
\hline Inner Mongolia ${ }^{\dagger}$ & 1 & 128 & 129 & 0.78 & 1.10 & 1.15 & -0.33 \\
\hline Chongqing & 1 & 86 & 87 & 1.15 & 1.25 & 1.91 & -0.10 \\
\hline Fujian & 2 & 105 & 107 & 1.87 & 1.76 & 1.55 & 0.11 \\
\hline Yunnan & 4 & 78 & 82 & 4.88 & 1.86 & 1.39 & 3.02 \\
\hline Shanxi & 7 & 79 & 86 & 8.14 & 2.10 & 2.14 & 6.04 \\
\hline Heilongjiang & 5 & 140 & 145 & 3.45 & 2.11 & 3.85 & 1.34 \\
\hline Guizhou & 3 & 103 & 106 & 2.83 & 2.40 & 1.66 & 0.43 \\
\hline Tianjin & 5 & 67 & 72 & 6.94 & 2.46 & 3.36 & 4.48 \\
\hline Anhui & 0 & 135 & 135 & 0.00 & 2.63 & 2.38 & -2.63 \\
\hline Guangxi & 0 & 93 & 93 & 0.00 & 2.96 & 2.59 & -2.96 \\
\hline Jiangxi & 1 & 124 & 125 & 0.80 & 2.99 & 3.48 & -2.19 \\
\hline Hunan & 2 & 109 & 111 & 1.80 & 3.33 & 2.29 & -1.53 \\
\hline Liaoning & 8 & 104 & 112 & 7.14 & 3.58 & 3.09 & 3.56 \\
\hline Shaanxi & 7 & 74 & 81 & 8.64 & 3.61 & 3.09 & 5.03 \\
\hline Beijing & 1 & 64 & 65 & 1.54 & 3.85 & 3.08 & -2.31 \\
\hline Hebei & 0 & 103 & 103 & 0.00 & 3.88 & 6.43 & -3.88 \\
\hline Jilin & 13 & 85 & 98 & 13.27 & 4.56 & 3.83 & 8.71 \\
\hline Shanghai & 4 & 60 & 64 & 6.25 & 4.67 & 4.50 & 1.58 \\
\hline Sichuan & 4 & 142 & 146 & 2.74 & 4.95 & 4.80 & -2.21 \\
\hline Hubei & 7 & 135 & 142 & 4.93 & 5.15 & 5.39 & -0.22 \\
\hline Henan & 2 & 66 & 68 & 2.94 & 5.24 & 6.26 & -2.30 \\
\hline Guangdong & 5 & 90 & 95 & 5.26 & 6.60 & 6.13 & -1.34 \\
\hline Shandong & 8 & 187 & 195 & 4.10 & 6.98 & 8.52 & -2.88 \\
\hline Zhejiang $^{\dagger}$ & 0 & 134 & 134 & 0.00 & 8.07 & 6.87 & -8.07 \\
\hline Jiangsu $^{\dagger}$ & 6 & 173 & 179 & 3.35 & 8.36 & 7.75 & -5.00 \\
\hline
\end{tabular}

Note. Provinces are ordered by their proportions of pharmaceutical firms in the country. ${ }^{\dagger}$ Provinces contained in our regression sample. 
Table A3. Numbers of Licensed and Unlicensed Firms Disclosed - Three-Province Sample

\begin{tabular}{|c|c|c|c|c|c|c|}
\hline \multirow[b]{3}{*}{ Year } & \multicolumn{4}{|c|}{ Jiangsu disclosed } & \multirow{2}{*}{\multicolumn{2}{|c|}{$\frac{\text { Jiangsu undisclosed }}{\text { Licensed }}$}} \\
\hline & \multicolumn{2}{|c|}{ Licensed } & \multicolumn{2}{|c|}{ Unlicensed } & & \\
\hline & Nonlocal & Local & Nonlocal & Local & Nonlocal & Local \\
\hline 2001 & 0 & 0 & 6 & 0 & 68 & 65 \\
\hline 2002 & 9 & 0 & 28 & 0 & 66 & 71 \\
\hline 2003 & 9 & 2 & 24 & 0 & 79 & 75 \\
\hline 2004 & 26 & 5 & 58 & 0 & 81 & 99 \\
\hline 2005 & 15 & 2 & 66 & 1 & 85 & 102 \\
\hline Total & 59 & 9 & 182 & 1 & 379 & 412 \\
\hline
\end{tabular}

\begin{tabular}{|c|c|c|c|c|c|c|}
\hline \multirow[b]{3}{*}{ Year } & \multicolumn{4}{|c|}{ Zhejiang disclosed } & \multirow{2}{*}{\multicolumn{2}{|c|}{$\begin{array}{c}\text { Zhejiang undisclosed } \\
\text { Licensed }\end{array}$}} \\
\hline & \multicolumn{2}{|c|}{ Licensed } & \multicolumn{2}{|c|}{ Unlicensed } & & \\
\hline & Nonlocal & Local & Nonlocal & Local & Nonlocal & Local \\
\hline 2001 & 1 & 0 & 7 & 0 & 169 & 40 \\
\hline 2002 & 13 & 0 & 16 & 0 & 178 & 40 \\
\hline 2003 & 16 & 0 & 10 & 0 & 208 & 41 \\
\hline 2004 & 19 & 0 & 14 & 0 & 220 & 47 \\
\hline 2005 & 31 & 0 & 40 & 0 & 213 & 44 \\
\hline \multirow[t]{3}{*}{ Total } & 80 & 0 & 87 & 0 & 988 & 212 \\
\hline & \multicolumn{4}{|c|}{ Inner Mongolia disclosed } & \multicolumn{2}{|c|}{ Inner Mongolia undisclosed } \\
\hline & \multicolumn{2}{|c|}{ Licensed } & \multicolumn{2}{|c|}{ Unlicensed } & \multicolumn{2}{|c|}{ Licensed } \\
\hline Year & Nonlocal & Local & Nonlocal & Local & Nonlocal & Local \\
\hline 2001 & 3 & 0 & 14 & 0 & 91 & 14 \\
\hline 2002 & 6 & 0 & 15 & 0 & 105 & 14 \\
\hline 2003 & 23 & 0 & 18 & 0 & 110 & 18 \\
\hline 2004 & 34 & 1 & 18 & 0 & 135 & 23 \\
\hline 2005 & 38 & 0 & 12 & 0 & 127 & 25 \\
\hline \multirow[t]{4}{*}{ Total } & 104 & 1 & 77 & 0 & 568 & 94 \\
\hline & \multicolumn{4}{|c|}{ Three provinces disclosed } & \multicolumn{2}{|c|}{ Three provinces undisclosed } \\
\hline & \multicolumn{2}{|c|}{ Licensed } & \multicolumn{2}{|c|}{ Unlicensed } & \multicolumn{2}{|c|}{ Licensed } \\
\hline & Nonlocal & Local & Nonlocal & Local & Nonlocal & Local \\
\hline Total & 243 & 10 & 346 & 1 & 1,935 & 718 \\
\hline
\end{tabular}

Note. The sample here is made up of all 569 licensed firms in the three provinces, comprising 2,906 observations. 


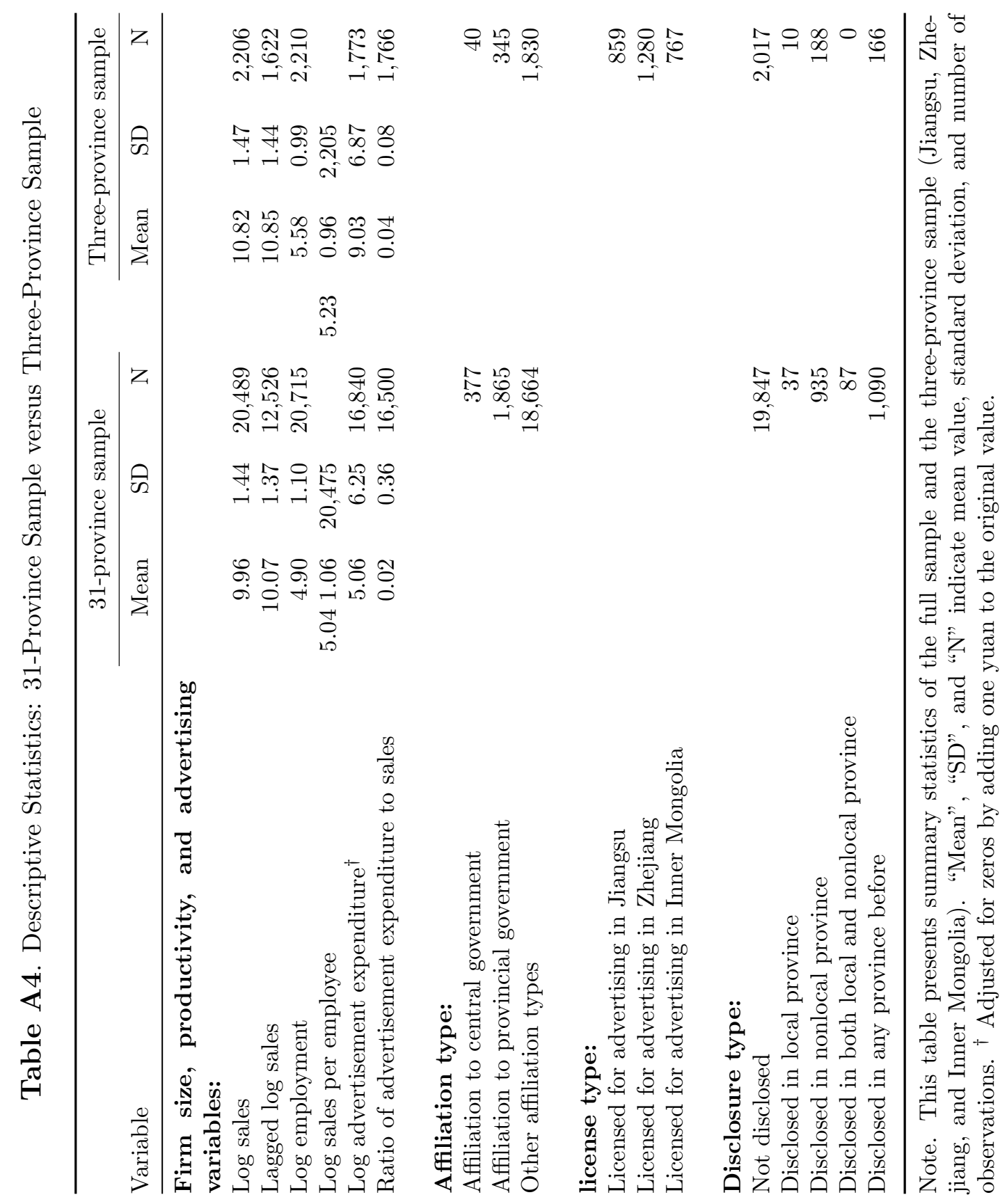




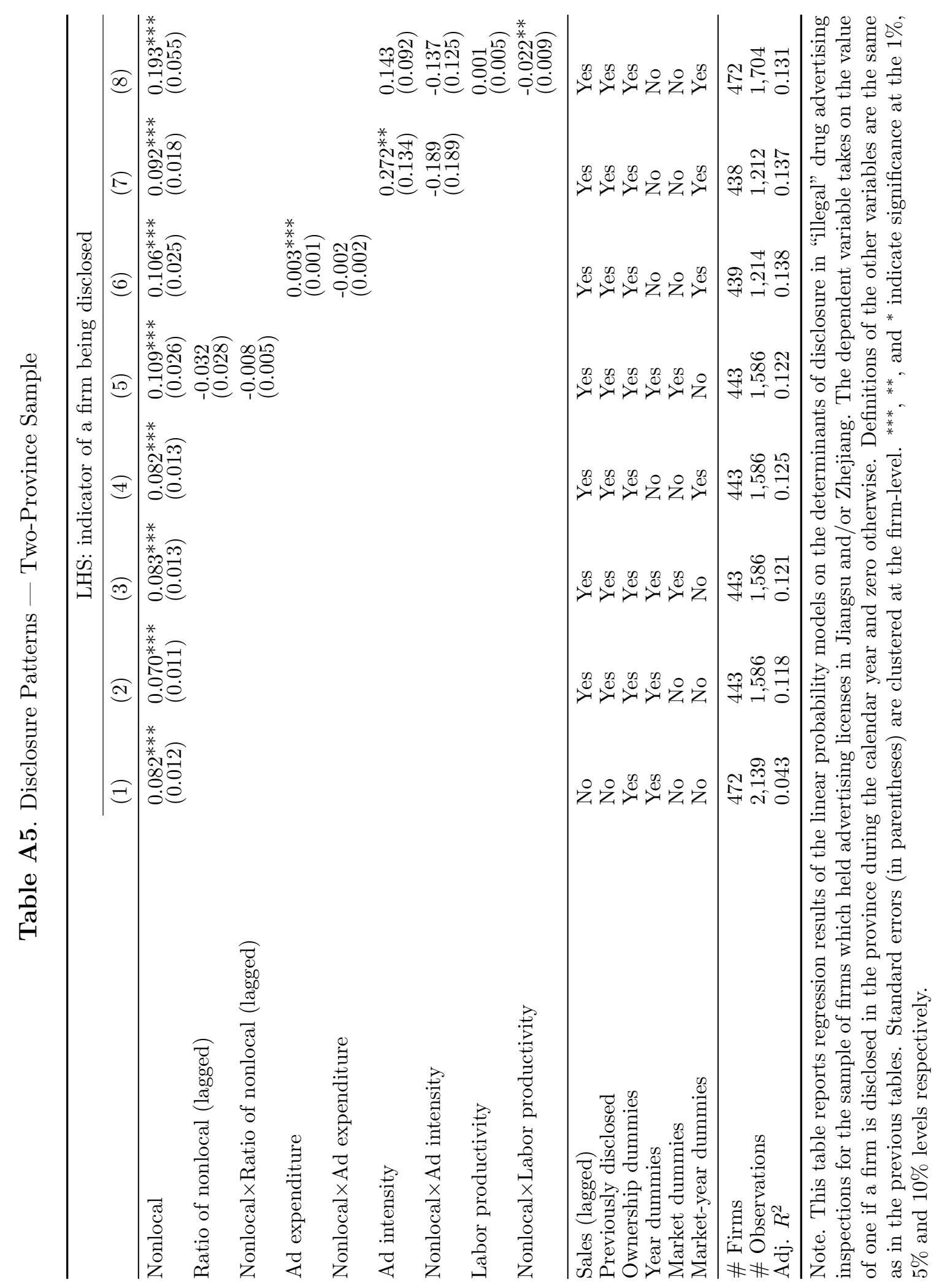




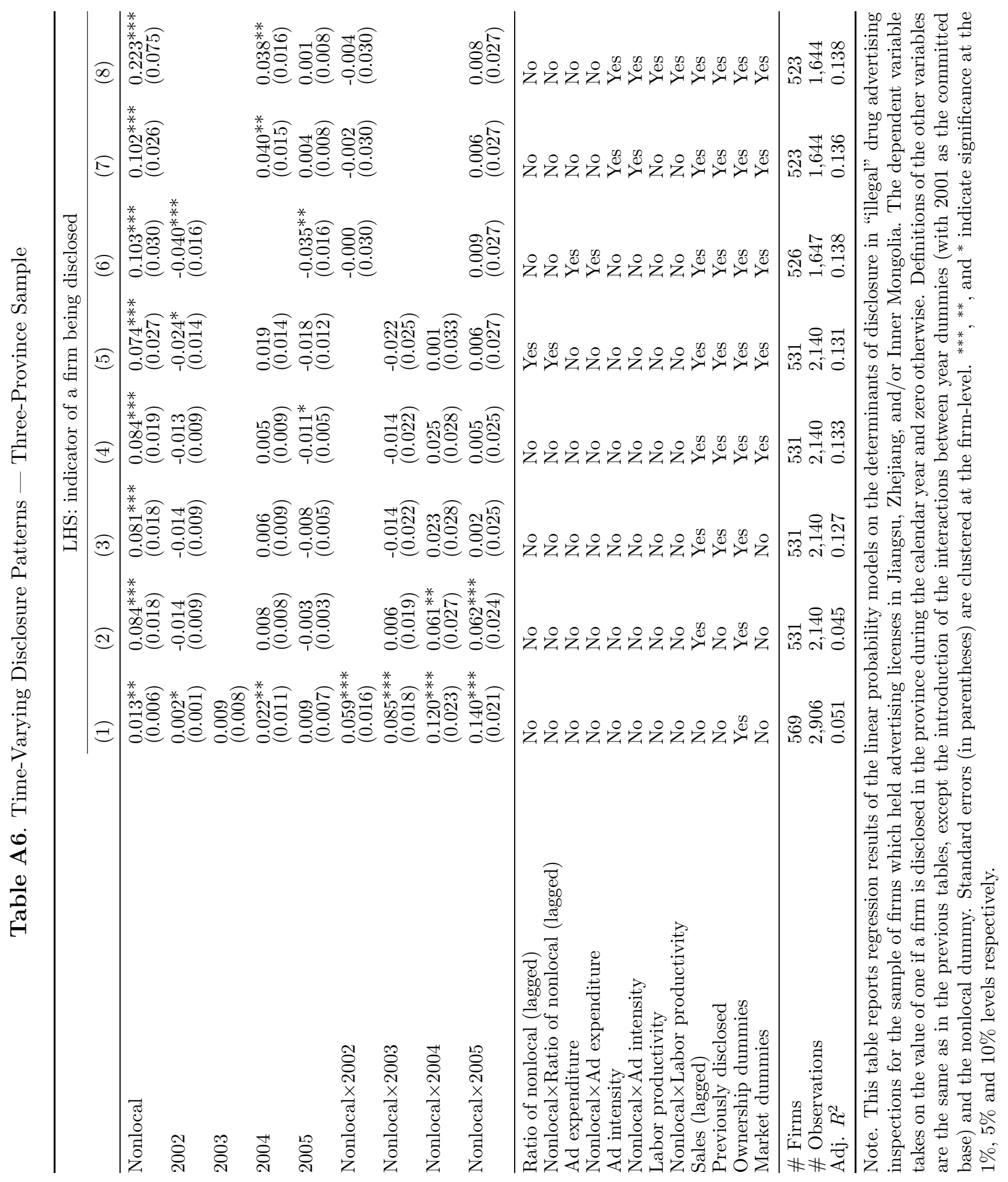




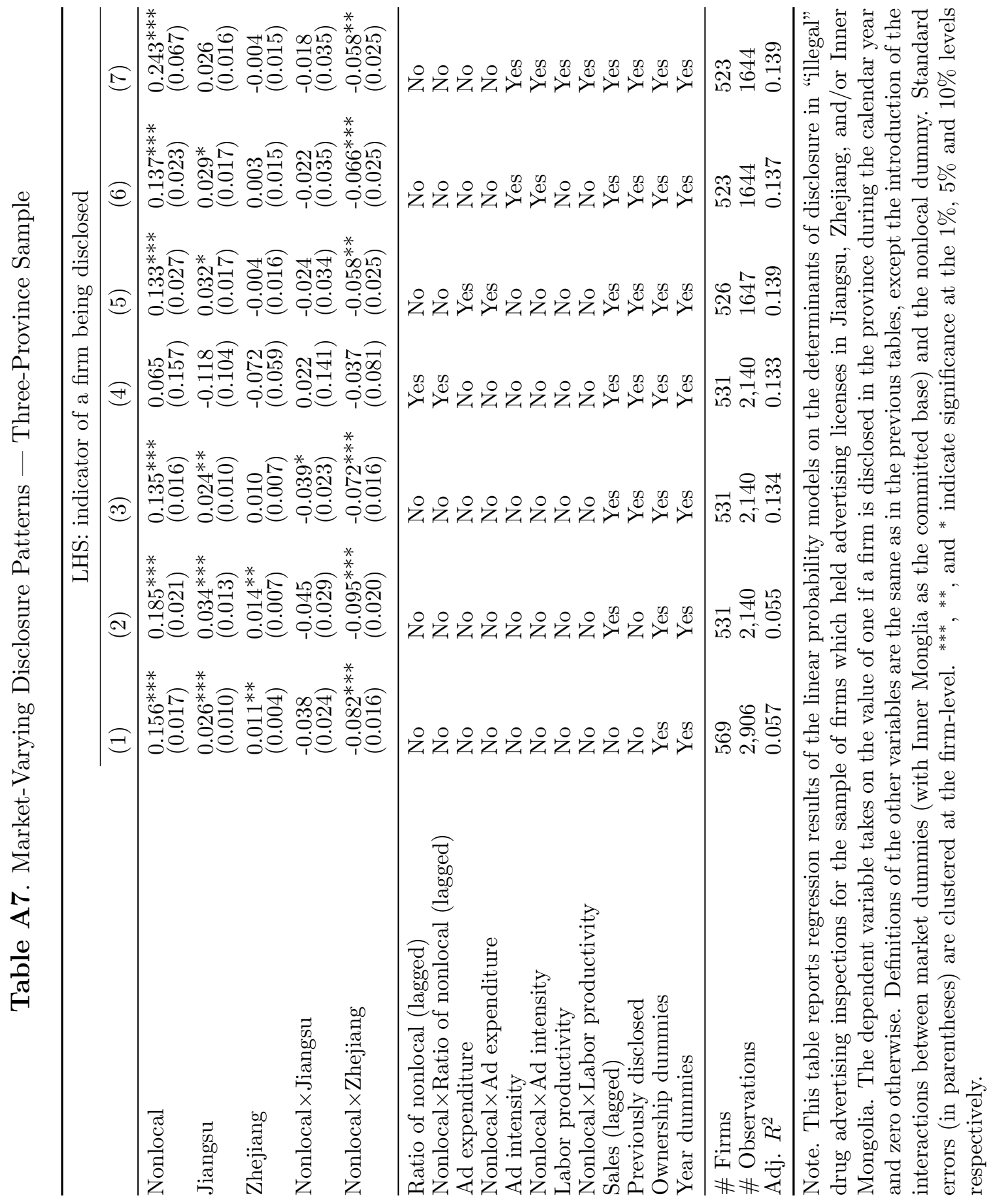


Table A8. Numbers of Firms by Location and Affiliation Type Three-Province Sample

\begin{tabular}{lrrrrr}
\hline & \multicolumn{5}{c}{ Government affiliation } \\
\cline { 2 - 4 } Location & None & Lower & Province & Central & Total \\
\hline Baseline sample: & 101 & 523 & 28 & 10 & 662 \\
Local & 250 & 1,495 & 449 & 50 & 2,244 \\
Nonlocal & 351 & 2,018 & 477 & 60 & 2,906 \\
Total & & & & & \\
Reduced sample: & 59 & 401 & 22 & 8 & 490 \\
Local & 162 & 1,110 & 338 & 40 & 1,650 \\
Nonlocal & 221 & 1,511 & 360 & 48 & 2,140 \\
Total & & & & \\
\hline
\end{tabular}

Note. This table reports the number of firms in all rows. "Baseline sample" indicates the statistics for the models where lagged values are not included, while "Reduced sample" indicates the statistics for the models estimated where lagged values are included. 


\section{Investigating the bias from selective disclosure between licensed and unli- censed firms}

As a first indication, it can be seen from Table A3 that virtually all $(346 / 347=99.7 \%)$ of the disclosed firms who got caught for unlicensed advertising were from outside the region. Given the fact that in reality some local firms may also engage in unlicensed advertising, this figure shows an extremely strong bias against nonlocal advertisers when local FDAs deal with unlicensed advertising activities. As a result, even if unlicensed advertising firms were included in our analysis, the discrimination effect would probably only be stronger than it is currently estimated.

Second, we run placebo tests on expanded samples where all pharmaceutical producers in 31 provinces are included. In panel A of Table A9, we apply the same specifications as in Table 2 on an enlarged sample of firm-province-year combinations by assuming that each firm advertises in the three provinces of Jiangsu, Zhejiang, and Inner Mongolia. As expected, the discrimination effect is now much lower $(0.5 \%-0.74 \%)$ but is positive and statistically significant in most specifications. In Panel B, using the same set of explanatory variables we resort to the bivariate probit model with the dependent variable in the additional equation (unreported) being a dummy for whether the firm was granted a license in one of the three provinces in a given year. The assumption is that every firm applies for licenses and advertises in the three provinces and the determination mechanism for licensing is the same as that for disclosure. The estimated marginal effect of being a nonlocal firm indicates a significantly positive discrimination effect, larger than our results Panel A but smaller than the baseline estimates in Table 2 of the main paper. In panel $\mathrm{C}$, the sample is further expanded with an even more radical assumption that each firm advertises in all 31 provinces of the country. Not surprisingly, the estimated discrimination effect is further reduced to below $6 \%$ but remains significantly different from zero in most specifications. Since all three assumptions exaggerate the actual number of firms who advertise or apply for licenses in the data, the estimates could be easily driven downward to zero or even negative values. Nevertheless in fact the estimates are still mostly positive and significant (albeit of smaller sizes), which we then take as further supporting evidence for the existence of a discrimination effect. 


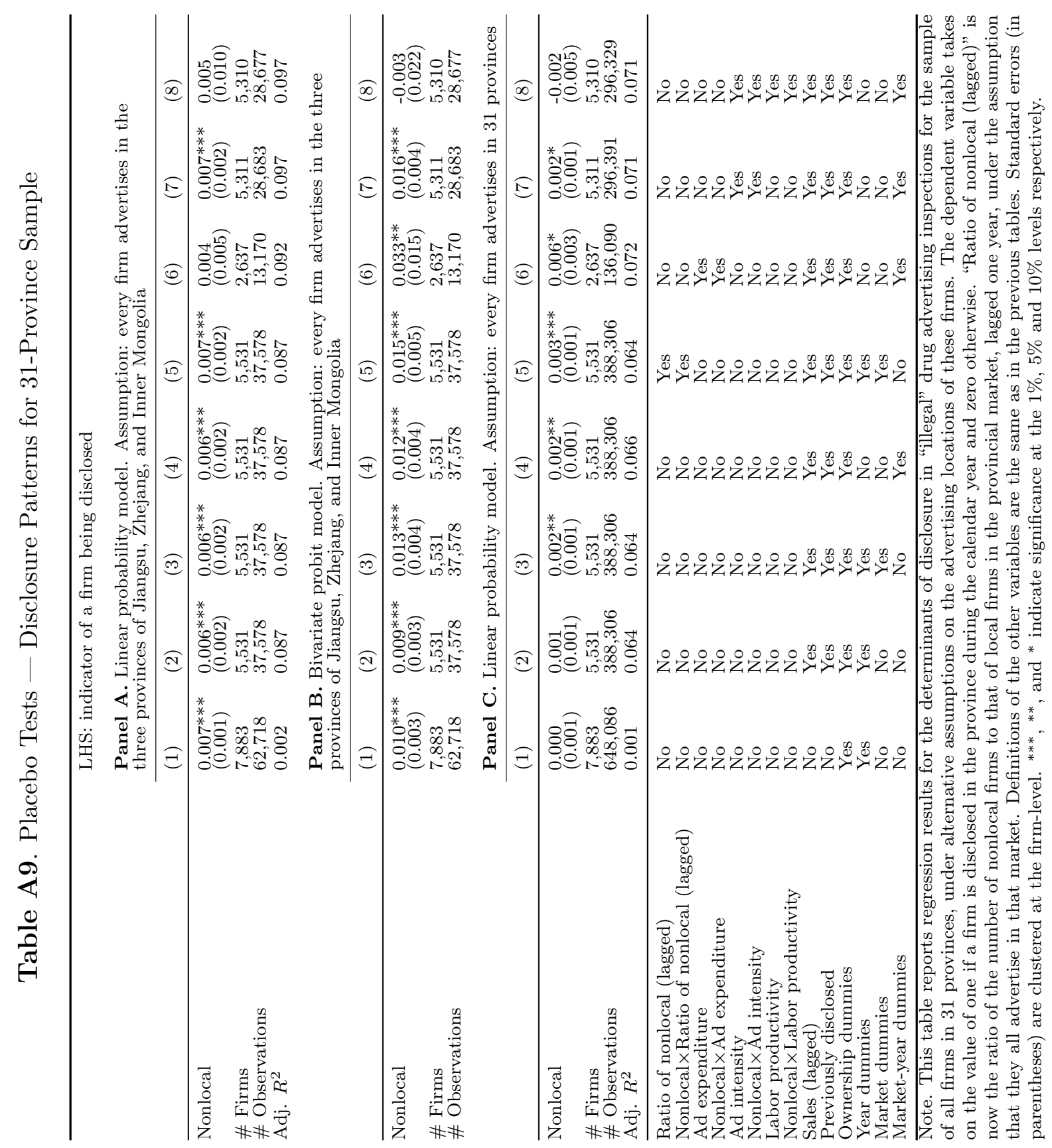

